\title{
User's Guide to the Weighted-Multiple-Linear Regression Program (WREG version 1.0)
}

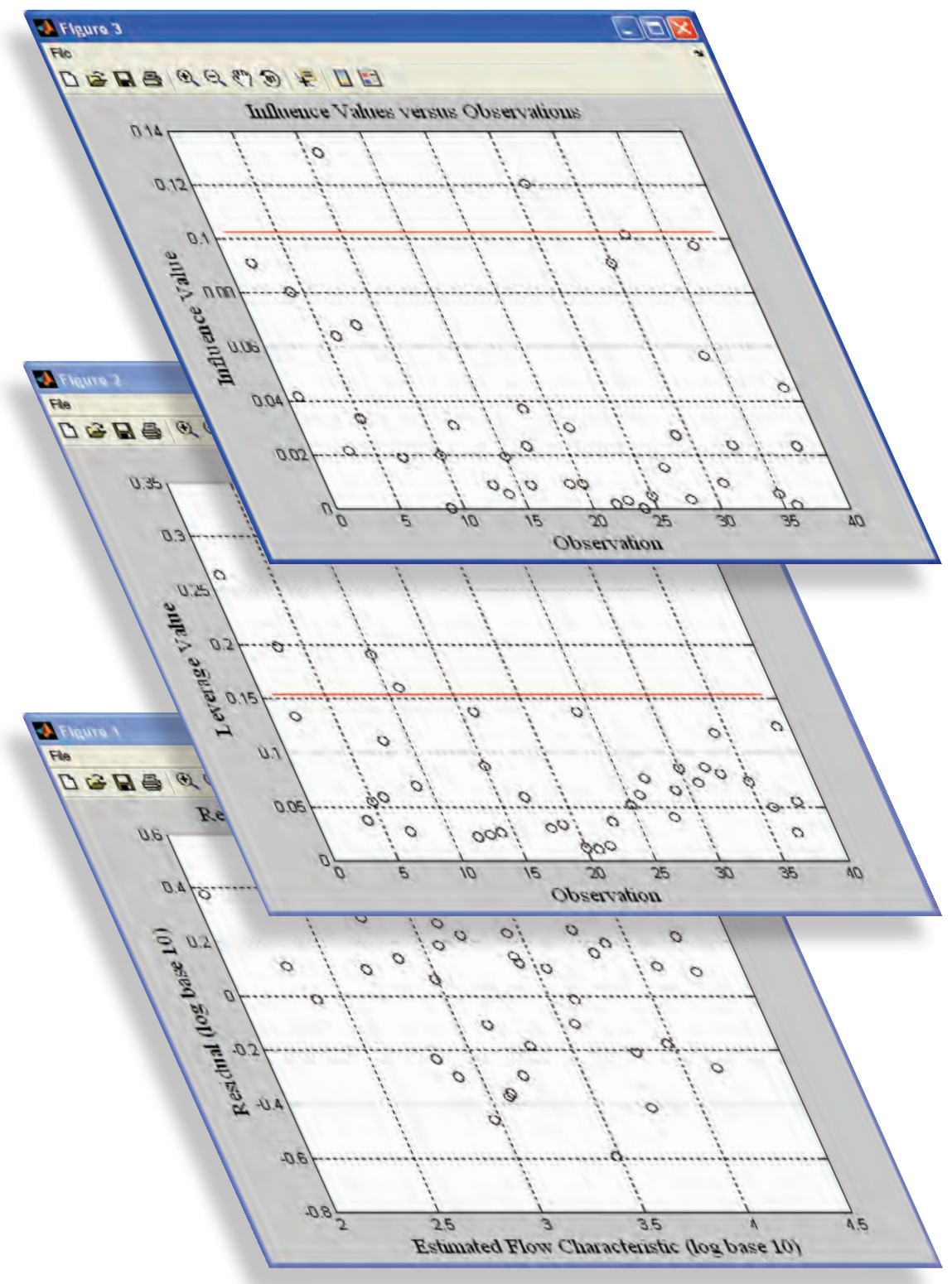

Techniques and Methods 4-A8 


\section{User's Guide to the Weighted- Multiple-Linear Regression Program (WREG version 1.0)}

By Ken Eng, Yin-Yu Chen, and Julie E. Kiang

Techniques and Methods 4-A8 


\section{U.S. Department of the Interior \\ KEN SALAZAR, Secretary \\ U.S. Geological Survey \\ Marcia K. McNutt, Director}

U.S. Geological Survey, Reston, Virginia: 2009

For more information on the USGS - the Federal source for science about the Earth, its natural and living resources, natural hazards, and the environment, visit http://www.usgs.gov or call 1-888-ASK-USGS.

For an overview of USGS information products, including maps, imagery, and publications, visit http://www.usgs.gov/pubprod.

To order this and other USGS information products, visit http://store.usgs.gov.

Any use of trade, product, or firm names is for descriptive purposes only and does not imply endorsement by the U.S. Government.

Although this report is in the public domain, permission must be secured from the individual copyright owners to reproduce any copyrighted materials contained within this report.

On the cover: Examples of plots resulting from analysis of data with the weighted-multiple-linear regression (WREG) program (version 1.0). 


\section{Contents}

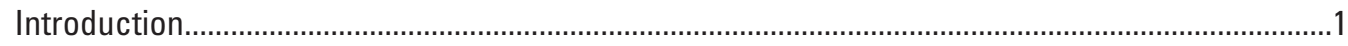

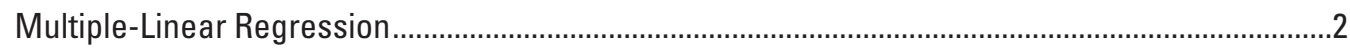

Independent and Dependent-Variable Transformations...........................................................2

Estimation of Multiple-Linear-Regression Parameters .......................................................................

Ordinary Least Squares (OLS) ........................................................................................

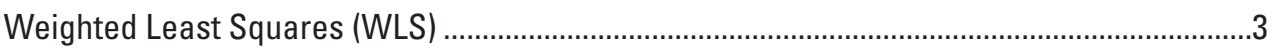

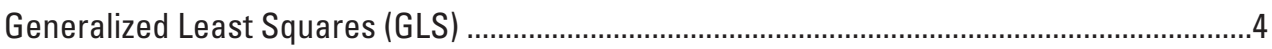

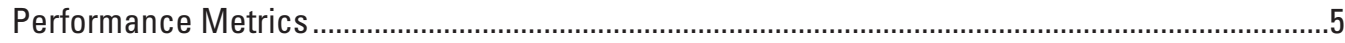

Model- and Time-Sampling Errors ....................................................................................

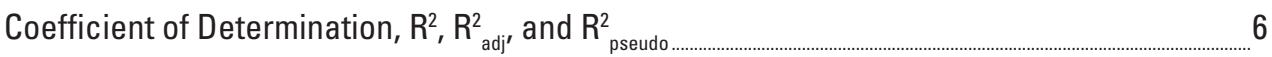

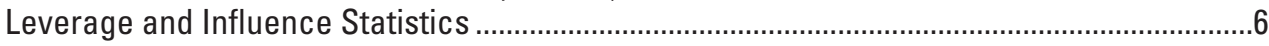

Significance of Regression Parameters ..........................................................................

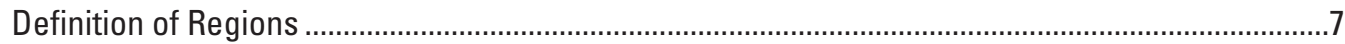

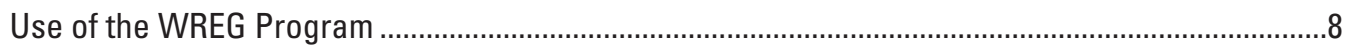

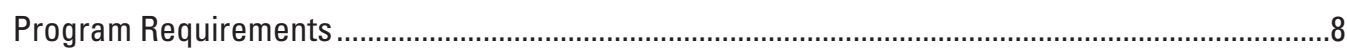

Installation

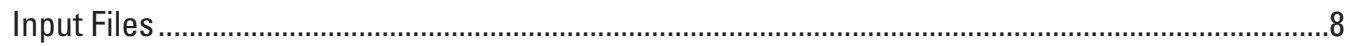

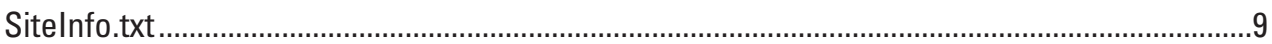

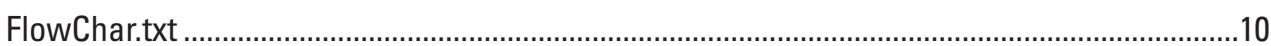

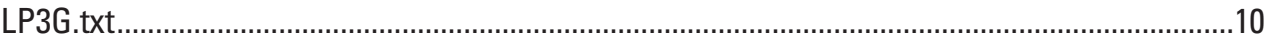

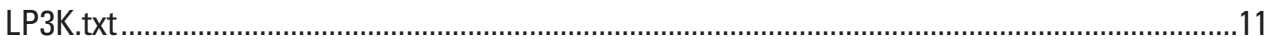

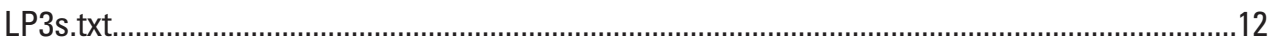

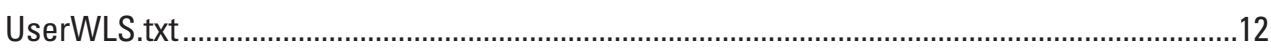

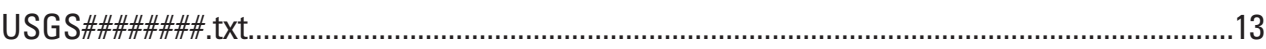

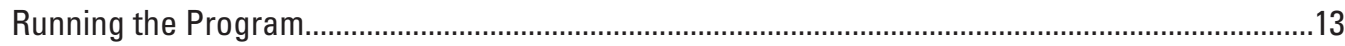

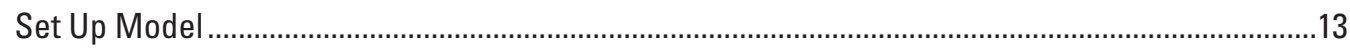

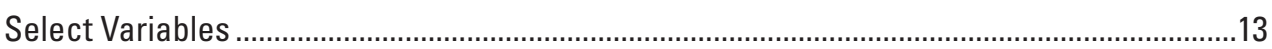

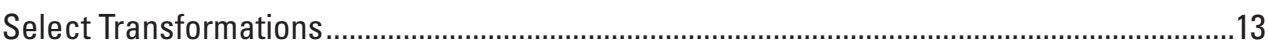

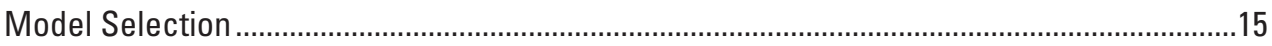

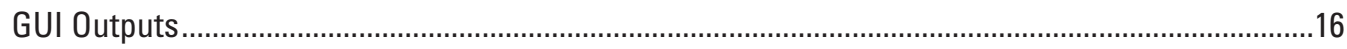

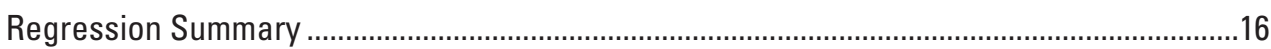

Residuals Versus Estimated Flow Characteristics ...........................................................17

Leverage Values Versus Observations.............................................................................17

Influence Values Versus Observations .............................................................................17

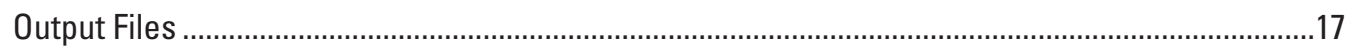

ConventionalOLS.txt, ConventionaIWLS.txt, and ConventionalGLS.txt..................................18

RegionofInfluenceOLS.txt, RegionoflnfluenceWLS.txt, and RegionoflnfluenceGLS.txt ........19

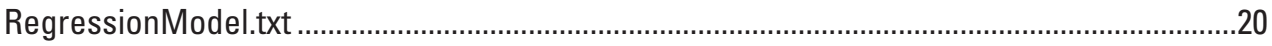

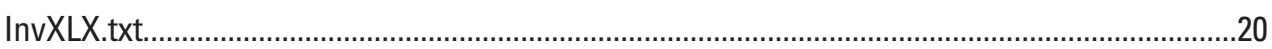

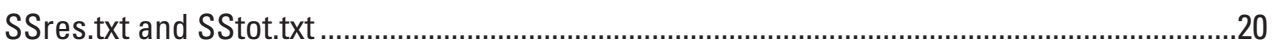

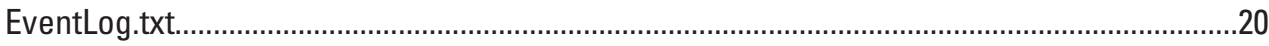




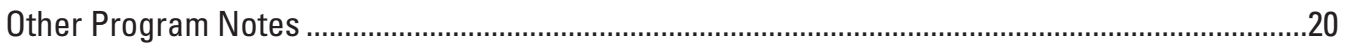

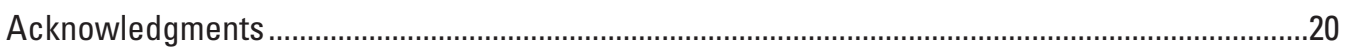

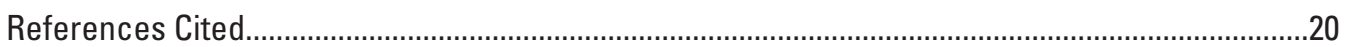

\section{Figures}

1. Examples of input file Sitelnfo.txt in text tab-delimited format .................................................

2. Example of input file FlowChar.txt in text tab-delimited format...............................................11

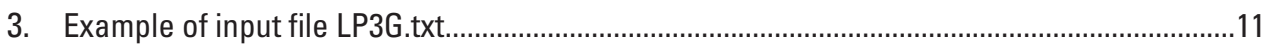

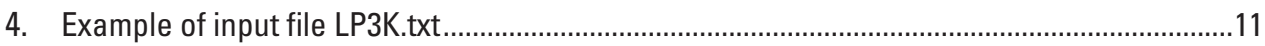

5. Example of input file LP3s.txt ......................................................................................12

6. Example of input file UserWLS.txt...................................................................................12

7. An example of a USGS\#\#\#\#\#\#\#.txt file for streamflow-gaging station 09183000 ....................13

8. Example of WREG window used to select variables to be used in the regression .................13

9. Examples of WREG window for selecting transformations ....................................................14

10. Example of WREG window for selecting the regression......................................................15

11. Example of WREG window for selecting parameters of the smoothing function for correlation as a function of distance between streamflow-gaging stations ..........................15

12. Example of WREG window for selecting option to include uncertainty in skew ....................16

13. WREG window showing the regression results for an OLS regression using the parameters and transformations specified in figure 9 ..........................................................16

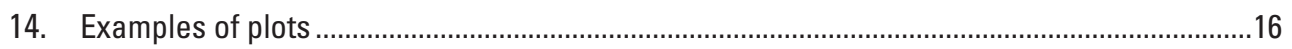

15. Example of output file ConventionalOLS.txt........................................................................17

16. Example of output file ConventionalWLS.txt .........................................................................18

17. Example of output file ConventionalGLS.txt....................................................................18

18. Example of output file Regionoflnfluence OLS.txt.............................................................19

19. Example of regression model equation shown by RegressionModel.txt ...............................20

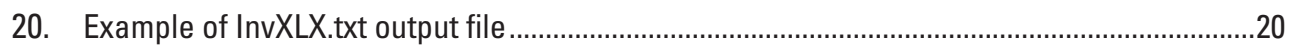

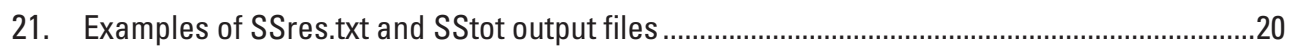

\section{Tables}

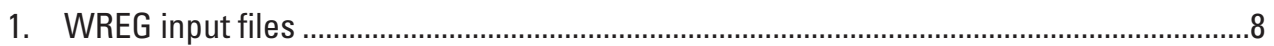

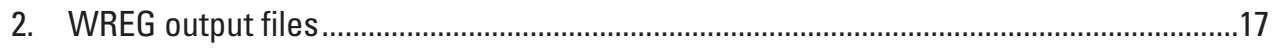




\section{Conversion Factors}

\begin{tabular}{lcl}
\hline \multicolumn{1}{c}{ Multiply } & \multicolumn{1}{c}{ By } & \multicolumn{1}{c}{ To obtain } \\
\hline & \multicolumn{2}{c}{ Length } \\
\hline inch (in.) & 2.54 & centimeter $(\mathrm{cm})$ \\
inch (in.) & 25.4 & millimeter $(\mathrm{mm})$ \\
foot (ft) & 0.3048 & meter $(\mathrm{m})$ \\
mile (mi) & 1.609 & kilometer $(\mathrm{km})$ \\
mile, nautical (nmi) & 1.852 & kilometer $(\mathrm{km})$ \\
yard (yd) & 0.9144 & meter $(\mathrm{m})$ \\
\hline
\end{tabular}





\title{
User's Guide to the Weighted-Multiple-Linear Regression Program (WREG version 1.0)
}

\author{
By Ken Eng, Yin-Yu Chen, ${ }^{1}$ and Julie E. Kiang
}

\section{Introduction}

Streamflow is not measured at every location in a stream network. Yet hydrologists, State and local agencies, and the general public still seek to know streamflow characteristics, such as mean annual flow or flood flows with different exceedance probabilities, at ungaged basins. The goals of this guide are to introduce and familiarize the user with the weightedmultiple-linear regression (WREG) program, and to also provide the theoretical background for program features. The program is intended to be used to develop a regional estimation equation for streamflow characteristics that can be applied at an ungaged basin, or to improve the corresponding estimate at continuous-record streamflow gages (henceforth referred to as simply gages) with short records. The regional estimation equation results from a multiple-linear regression that relates the observable basin characteristics, such as drainage area, to streamflow characteristics (for example, Thomas and Benson, 1970; Giese and Mason, 1993; Ries and Friesz, 2000; Eng and others, 2005; Eng and others, 2007a; Eng and others, 2007b; Kenney and others, 2007; Funkhouser and others, 2008).

The general multiple-linear regression for estimating a streamflow characteristic can be given by

$$
y_{i}=\beta_{0}+\beta_{1} x_{i 1}+\beta_{2} x_{i 2}+\ldots+\beta_{k} x_{i k}+\delta_{i}
$$

where $\quad y$ is the streamflow characteristic (dependent variable),

$x_{i k}$ are basin characteristics (independent variables),

$i(=1,2,3, \ldots, n)$ is the index for gage $i$,

$k$ is the number of basin characteristics,

$\beta_{0}, \beta_{1}, \beta_{2}$, and $\beta_{k}$ are the regression parameters, and

$\delta_{i}$ is the model error.

A critical issue in regional analyses is to understand the various sources of variability and error in the data. By understanding these sources, a user can select the appropriate approaches to estimate the regression parameters in equation 1 , and the appropriate network of gages forming the region used to develop an estimate. Three approaches to estimate

${ }^{1}$ Former U.S. Geological Survey volunteer. regression parameters are provided in the WREG program: ordinary-least-squares (OLS), weighted-least-squares (WLS), and generalized-least-squares (GLS). All three approaches are based on the minimization of the sum of squares of differences between the gage values and the line or surface defined by the regression. The OLS approach is appropriate for many problems if the $\delta_{i}$ values are all independent of one another, and they have the same variance. Streamflow characteristics are estimated at gages using the available length of streamflow record. Because the length of record varies among gages, the precision of these estimates also varies, meaning that different $\delta_{i}$ values will have different variances.

A way to address the variation in the precision of estimated streamflow characteristics at each gage is to weight gages differently using WLS or GLS. A WLS approach reflects the precision of the estimated streamflow characteristic at that gage. An additional issue is that concurrent flows observed at different gages in a region exhibit cross correlations. If these correlations are not represented in a regional analysis, the regression parameters are less precise, and estimators of precision are inaccurate. A regional analysis that accounts for the precision of estimated streamflow characteristics, and the cross correlations among these characteristics, is known as GLS.

In addition to the variation and error in the data, the regression parameters in equation 1 are impacted by the choice of a network of gages forming a region. In a "conventional" regression, a region can be defined in several ways before a multiple-linear-regression study is initiated, such as by political boundaries or by physiographic boundaries. Within the context of "conventional" regressions, regions can also be defined during the regression study by using geographic information as an independent variable in the regression. Such regions can be defined using a variety of criteria, such as geographic grouping of similar residuals from an overall regression (Wandle, 1977), use of watershed boundaries (Neely, 1986), or physiographic characteristics. When performing a conventional analysis, a user of WREG must define the regions before using the program. WREG allows the user to perform conventional regressions using either OLS, WLS, or GLS.

An alternative to the conventional approach of pre-defining regions using political or physiographic boundaries is to define a region for each location of interest. This "region-of-influence" (RoI) regression approach defines a region and associated 
multiple-linear regression for every ungaged basin (for example, Acreman and Wiltshire, 1987; Burns, 1990; Tasker and others, 1996; Merz and Blöschl, 2005; Eng and others, 2005; Eng and others, 2007a; Eng and others, 2007b). A regression is formed on a subset of gages for which the values of independent variables are, by some measure, closest to those at the ungaged basin of interest. While the WREG program allows testing of RoI regressions, the application of RoI regression to ungaged basins must be accomplished using other programs, such as the National Streamflow Statistics (NSS) Program (Ries, 2006).

The first part of this report provides an overview of the multiple-linear regression techniques that are employed by WREG. It is followed by a step-by-step guide to the actual use of the program, including a description of the input files, the use of the graphical user interface, and an explanation of the output files.

\section{Multiple-Linear Regression}

In practice, the dependent variable, $y_{i}$, in equation 1 is an estimate, $\hat{y}_{i}$, often obtained from a limited sample size at each gage. The associated time-sampling error for the $i^{\text {th }}$ gage, $\eta_{i}$, is defined by

$$
\eta_{i}=\hat{y}_{i}-y_{i}
$$

Substituting equation 2 into equation 1 gives

$$
\hat{y}_{i}=\beta_{0}+\beta_{1} x_{i 1}+\beta_{2} x_{i 2}+\ldots+\beta_{k} x_{i k}+\varepsilon_{i},
$$

where $\quad \varepsilon_{i}=\delta_{i}+\eta_{i}\left(\delta_{i}\right.$ as given by equation 1$)$.

The $\eta_{i}$ values from gages close together will generally be correlated, because the finite sample of observed streamflows at one gage temporally overlaps the sample from another and temporal variations of streamflows are spatially correlated. Thus, the cross correlation between $\eta_{i}$ and $\eta_{j}$ for gage $i$ and $j$ will depend upon the cross correlation of concurrent flows at the two gages, and the number of concurrent years of record included in the dataset.

For a collection of gages with associated dependent and independent variables, equation 3 can be conveniently written in matrix notation as

$$
\hat{\mathbf{Y}}=\mathbf{X} \boldsymbol{\beta}+\boldsymbol{\varepsilon}
$$

where

$$
\hat{\mathbf{Y}}=\left[\begin{array}{c}
\hat{y}_{1} \\
\hat{y}_{2} \\
\vdots \\
\hat{y}_{i}
\end{array}\right] \mathbf{X}=\left[\begin{array}{ccccc}
1 & x_{11} & x_{12} & \cdots & x_{1 k} \\
1 & x_{21} & x_{22} & \cdots & x_{2 k} \\
\vdots & \vdots & \vdots & & \vdots \\
1 & x_{i 1} & x_{i 2} & \cdots & x_{i k}
\end{array}\right] \boldsymbol{\beta}=\left[\begin{array}{c}
\beta_{0} \\
\beta_{1} \\
\beta_{2} \\
\vdots \\
\beta_{k}
\end{array}\right] \boldsymbol{\varepsilon}=\left[\begin{array}{c}
\varepsilon_{1} \\
\varepsilon_{2} \\
\vdots \\
\varepsilon_{i}
\end{array}\right],
$$

and the total error, $\boldsymbol{\varepsilon}$, is a random variable with a mean equal to zero and variance equal to $\sigma_{\varepsilon}^{2}$.

\section{Independent and Dependent-Variable Transformations}

The independent and dependent variables used in equation 5 can be transformed to obtain a linear relationship between the $\hat{\mathbf{Y}}$ and $\mathbf{X}$ values. Common transformations include log (base 10), log (natural), and addition or subtraction of a constant. A user of WREG must choose appropriate transformations in the graphical user interface (GUI) before a multiple-linear regression is performed. A general transformation equation used by WREG is given as

$$
V_{\text {new }}=f\left[\left(C 1(V)^{C 2}+C 3\right)^{C 4}\right] \text {, }
$$

where

$V$ is the dependent or independent variable to be transformed,

$V_{n e w}$ is the transformed independent or dependent variable,

$f$ is either the $\log$ (base 10), $\log$ (natural), or exponential function, or a transformation can be omitted.

$C 1, C 2, C 3$, and $C 4$ are constants entered by the user.

Use of equation 6 for transforming variables is further discussed in the section of this report titled Select Transformations.

\section{Estimation of Multiple-Linear- Regression Parameters}

Following transformations of the dependent and independent variables, the transformed variables are used in WREG to estimate multiple-linear-regression parameters. When using any of the least squares regression approaches (OLS, WLS, or GLS), the regression parameters are estimated by

$$
\hat{\boldsymbol{\beta}}=\left(\mathbf{X}^{T} \boldsymbol{\Lambda}^{-1} \mathbf{X}\right)^{-1} \mathbf{X}^{T} \boldsymbol{\Lambda}^{-1} \hat{\mathbf{Y}}
$$

where $\mathbf{X}^{T}$ is the transpose of matrix $\mathbf{X}$,

$\boldsymbol{\Lambda}^{-1}$ is the inverse of the weighting matrix $\boldsymbol{\Lambda}\left(\mathbf{I}=\boldsymbol{\Lambda}^{-1} \boldsymbol{\Lambda}\right.$, where $\mathbf{I}$ is equal to the identity matrix).

The $\boldsymbol{\Lambda}$ matrix is constructed differently for OLS, WLS, and GLS, as described in the following sections. Once $\hat{\boldsymbol{\beta}}$ is determined, it can be used to estimate the regression estimate of $\hat{y}$ at the $i^{\text {th }}$ gage, $\hat{y}_{i R}$, as

$$
\hat{y}_{i R}=\hat{\beta}_{o}+\hat{\beta}_{1} x_{i, 1}+\hat{\beta}_{2} x_{i, 2}+\ldots+\hat{\beta}_{k} x_{i, k}
$$

However, a user should first check if the regression is adequate.

The estimators of $\boldsymbol{\Lambda}$ used in WREG for WLS and GLS approaches are applicable only to frequency-based streamflow characteristics. Alternative estimators of $\boldsymbol{\Lambda}$ to those presented in this manual can be explored using a user-defined option in 
WREG (see section UserWLS.txt) for non-frequency-based streamflow characteristics, such as flow-duration exceedences.

\section{Ordinary Least Squares (OLS)}

For the OLS approach, $\boldsymbol{\beta}$ is estimated by (for example, Montgomery and others, 2001)

$$
\hat{\boldsymbol{\beta}}=\left(\mathbf{X}^{T} \boldsymbol{\Lambda}_{O L S}^{-1} \mathbf{X}\right)^{-1} \mathbf{X}^{T} \boldsymbol{\Lambda}_{O L S}^{-1} \hat{\mathbf{Y}}=\left(\mathbf{X}^{T} \mathbf{X}\right)^{-1} \mathbf{X}^{T} \hat{\mathbf{Y}}
$$

where $\quad \boldsymbol{\Lambda}_{O L S}=\mathbf{I}=\left[\begin{array}{cccc}1 & 0 & \cdots & 0 \\ 0 & 1 & & \vdots \\ \vdots & & \ddots & 0 \\ 0 & \cdots & 0 & 1\end{array}\right]$.

The OLS approach is suitable for estimating regression parameters when there is no variation in the precision of calculated dependent variables among gages, and the errors in equation 5 are independent of each other.

\section{Weighted Least Squares (WLS)}

For the WLS approach, $\boldsymbol{\beta}$ is estimated by (for example, Tasker, 1980)

$$
\hat{\boldsymbol{\beta}}=\left(\mathbf{X}^{T} \boldsymbol{\Lambda}_{W L S}^{-1} \mathbf{X}\right)^{-1} \mathbf{X}^{T} \boldsymbol{\Lambda}_{W L S}^{-1} \hat{\mathbf{Y}},
$$

where $\quad \boldsymbol{\Lambda}_{W L S}$ is the covariance matrix used to determine weights.

The components of the $\boldsymbol{\Lambda}_{W L S}$ matrix are a function of the type and source of the dependent variable. As with the OLS approach, the WLS approach is suitable when the errors in equation 5 are independent. However, for the WLS approach, weights in the weighting matrix are assigned so that gages that have more "reliable" estimates of streamflow characteristics have larger weights.

For streamflow characteristics calculated from a logPearson Type III frequency analysis (Bulletin 17B of the Interagency Advisory Committee on Water Data, 1982), Tasker (1980) provides a method for estimation of $\boldsymbol{\Lambda}_{W L S}$ that is used by WREG for this option:

$$
\hat{\Lambda}_{W L S, i j}=\left\{\begin{array}{cc}
\sigma_{\delta}^{2}+c_{1}\left(\frac{1}{m_{i}}\right) & (i=j) \\
0 & (i \neq j)
\end{array},\right.
$$

where

$$
\begin{gathered}
c_{1}=\max \left[0, \bar{\sigma}^{2}\left(1+\frac{\bar{K}^{2}}{2}\left(1+0.75 \bar{G}^{2}\right)+\bar{K} \bar{G}\right)\right], \text { and } \\
\sigma_{\delta}^{2}=\max \left[0, \sigma_{O L S}^{2}-c_{1}\left(\frac{1}{n} \sum_{p=1}^{n} \frac{1}{m_{p}}\right)\right],
\end{gathered}
$$

where $\sigma_{\delta}^{2}$ is the model-error variance,

$m_{i}$ is the record length for the $i^{\text {th }}$ gage,

$\sigma_{O L S}^{2}$ is the observed mean-square error (MSE)

of estimate using ordinary-least-squares approach,

$\bar{K}$ is the arithmetic average of the log-Pearson Type

III deviates for all gages in the regression, and

$\bar{G}$ is the arithmetic average of the skew values at all gages (either at-gage skew, $g$, or weighted skew, $G_{w}$; explained below).

The log-Pearson Type III deviate values are a function of probability of exceedence and $g$ (Interagency Advisory Committee on Water Data, 1982). $\bar{\sigma}$ is the arithmetic average of standard deviation of the annual-time series of the streamflow characteristic estimated by regression. This "sigma regression" is determined by OLS regression of the standard deviation of the annual-time series at each gage against basin characteristics at each gage (Tasker and Stedinger, 1989),

$$
\sigma_{i}=\alpha_{0}+\beta_{\sigma 1} x_{i 1}+\beta_{\sigma 2} x_{i 2}+\cdots+\beta_{\sigma k} x_{i k}+\varepsilon_{\sigma},
$$

where

$\sigma_{i}$ is the standard deviation of the annual-time series of the streamflow characteristic for the $i^{\text {th }}$ gage,

$x_{i k}$ is the $k^{\text {th }}$ basin characteristic for the $i^{\text {th }}$ gage,

$\alpha_{0}, \beta_{\sigma 1}, \beta_{\sigma 2}$, and $\beta_{\sigma k}$ are parameters, and

$\varepsilon_{\sigma}$ is the model error for the sigma regression.

The $\sigma_{i}$ values are a required input into the WREG program as discussed in section LP3s.txt.

The weighted skew for the $i^{\text {th }}$ gage is given by (Bulletin 17B of the Interagency Advisory Committee on Water Data, 1982)

$$
G_{w, i}=\omega_{i} g_{i}+\left(1-\omega_{i}\right) G_{R, i}
$$

where $G_{R, i}$ is the regional skew estimate applicable to the $i^{\text {th }}$ gage, and

$$
\omega_{i}=\left(\frac{\operatorname{MSE}\left(G_{R}\right)}{\operatorname{MSE}\left(g_{i}\right)+\operatorname{MSE}\left(G_{R}\right)}\right),
$$

where $\operatorname{MSE}\left(g_{i}\right)$ is equal to the estimated mean square error of the skew value at the gage, and

$\operatorname{MSE}\left(G_{R}\right)$ is the estimated mean square error of the regional skew values.

A variety of methods are available to determine $G_{R}$ values (Bulletin 17B of the Interagency Advisory Committee on Water Data,1982). Either $g$ or $G_{w}$ values are required input to WREG program as discussed in section LP3G.txt.

An alternative approach to calculating $\sigma_{\delta}^{2}$ is presented by Stedinger and Tasker (1986). Their estimator is demonstrated to be more precise than equation 13 , but their study did not include a mix of approaches to compute streamflow characteristics at partial-record-stream gages (Funkhouser and others, 2008). Use of equations 12 to 14 within the WREG program allows future versions to account for this mix of approaches for partial-record-stream gages. 


\section{Generalized Least Squares (GLS)}

For streamflow characteristics calculated from a log-Pearson Type III frequency analysis, a GLS approach described by Stedinger and Tasker (1985) builds on the WLS approach by accounting for both correlated streamflows and time-sampling errors. This GLS approach estimates the $\boldsymbol{\beta}$ values by

$$
\hat{\boldsymbol{\beta}}=\left(\mathbf{X}^{T} \boldsymbol{\Lambda}_{G L S}^{-1} \mathbf{X}\right)^{-1} \mathbf{X}^{T} \boldsymbol{\Lambda}_{G L S}^{-1} \hat{\mathbf{Y}},
$$

where $\boldsymbol{\Lambda}_{G L S}$ is a matrix containing the estimates of the covariances of $\varepsilon_{i}$ among gages.

The main diagonal elements of $\boldsymbol{\Lambda}_{G L S}$ thus include a part associated with the model error, $\delta_{i}$, and all elements include the effect of the time-sampling error, $\eta_{i}$. In Tasker and Stedinger (1989), $\boldsymbol{\Lambda}_{G L S}$ is estimated by

$$
\hat{\Lambda}_{G L S, i j}=\left\{\begin{array}{cc}
\sigma_{\delta i}^{2}+\frac{\sigma_{i}^{2}}{m_{i}}\left[1+K_{i} G_{i}+0.5 K_{i}^{2}\left(1+0.75 G_{i}^{2}\right)\right] & (i=j) \\
\frac{\hat{\rho}_{i j} \sigma_{i} \sigma_{j} m_{i j}}{m_{i} m_{j}}\left[1+0.5 K_{i} G_{i}+0.5 K_{j} G_{j}+0.5 K_{i} K_{j}\left(\hat{\rho}_{i j}+0.75 G_{i} G_{j}\right)\right] & (i \neq j)
\end{array}\right.
$$

where $i$ and $j$ are indices of locations of gages in the region of interest,

$G_{i}$ and $G_{j}$ are skew values equal to either $g$ or $G_{w}$ (equation 16) values for gages $i$ and $j$,

$m_{i}$ and $m_{j}$ are record lengths for gages $i$ and $j$,

$m_{i j}$ is the concurrent record length for gages $i$ and $j$, and

$\rho_{i j}$ is an estimated value for the cross-correlation of the time series of flow values used to calculate the streamflow characteristic at gages $i$ and $j$.

Values of the cross-correlation are estimated approximately by (Tasker and Stedinger, 1989)

$$
\hat{\rho}_{i j}=\theta^{\left[\frac{d_{i j}}{\alpha d_{i j}+1}\right]},
$$

where $d_{i j}$ is the distance between gages $i$ and $j$ in miles, and

$\theta$ and $\alpha$ are dimensionless parameters estimated from data as discussed in section Model

Selection.

The $\sigma_{\delta_{i}}^{2}$ values in equation 19 and the $\hat{\boldsymbol{\beta}}$ values in equation 18 are jointly determined by iteratively searching for a nonnegative solution to (Stedinger and Tasker, 1985)

$$
(\hat{\mathbf{Y}}-\mathbf{X} \hat{\boldsymbol{\beta}})^{T} \boldsymbol{\Lambda}_{G L S}^{-1}(\hat{\mathbf{Y}}-\mathbf{X} \hat{\boldsymbol{\beta}})=n-(k+1)
$$

Equation 19 does not account for error associated with estimating $G$. Depending on the actual magnitude of errors in estimation of skew, this additional error may unduly influence the estimation of $\boldsymbol{\beta}$. Griffis and Stedinger (2007) proposed an approach to account for the uncertainty in the skew estimates in $\boldsymbol{\Lambda}_{G L S}$, and this approach is used as an option by WREG. As implemented in WREG, this option assumes that weighted skews are provided by the user, and so this option should be activated only when weighted skews were used. The modified $\boldsymbol{\Lambda}_{G L S}$ matrix, $\boldsymbol{\Lambda}_{G L S, \text { skew }}$, is given by

$$
\hat{\Lambda}_{G L S, \text { skew }, i j}=\left\{\begin{array}{l}
\sigma_{\delta i}^{2}+\frac{\sigma_{i}^{2}}{m_{i}}\left[1+K_{i} G_{i}+0.5 K_{i}^{2}\left(1+0.75 G_{i}^{2}\right)+\omega_{i} K_{i} \frac{\partial K_{i}}{\partial G_{i}}\left(3 G_{i}+0.75 G_{i}^{3}\right)\right. \\
\left.+\omega_{i}^{2}\left(\frac{\partial K_{i}}{\partial G_{i}}\right)^{2}\left(6+9 G_{i}^{2}+1.875 G_{i}^{4}\right)\right]+\left(1-\omega_{i}\right)^{2} \sigma_{i}^{2} M S E\left(G_{R}\right)\left(\frac{\partial K_{i}}{\partial G_{i}}\right)^{2} \quad(i=j) \\
\frac{\hat{\rho}_{i j} \sigma_{i} \sigma_{j} m_{i j}}{m_{i} m_{j}}\left[1+0.5 K_{i} G_{i}+0.5 K_{j} G_{j}+0.5 K_{i} K_{j}\left(\hat{\rho}_{i j}+0.75 G_{i} G_{j}\right)\right. \\
\left.+0.5 \omega_{i} K_{j} G_{i} \frac{\partial K_{i}}{\partial G_{i}}\left(3 \hat{\rho}_{i j}+0.75 G_{i} G_{j}\right)+\omega_{i} \omega_{j} \sigma_{i} \sigma_{j} \frac{\partial K_{i}}{\partial G_{i}} \frac{\partial K_{j}}{\partial G_{j}} \operatorname{COV}\left[g_{i}, g_{j}\right]\right]
\end{array} \quad(i \neq j)\right]
$$


where $\frac{\partial K_{i}}{\partial G_{i}}$ and $\frac{\partial K_{j}}{\partial G_{j}}$ are the partial derivatives for gages $i$ 1976) approximation for $K$ given as

$\frac{\partial K}{\partial G}=\frac{\left(z_{p}^{2}-1\right)}{6}+\frac{\left(z_{p}^{3}-6 z_{p}\right) G}{54}-\frac{\left(z_{p}^{2}-1\right) G^{2}}{72}+\frac{z_{p} G^{3}}{324}+\frac{5 G^{4}}{23,328}$,

where $z_{p}$ is the standard normal deviate corresponding to probability $p$.

The $\mathrm{COV}\left[g_{i}, g_{j}\right]$ in equation 22 is the covariance between the skew values at gages $i$ and $j$, and is given by

$$
\operatorname{COV}\left[g_{i}, g_{j}\right]=\rho_{g_{i} g_{j}} \sqrt{\operatorname{Var}\left(g_{i}\right) \operatorname{Var}\left(g_{j}\right)},
$$

where $\rho_{g_{i} g_{j}}$ is estimated by (Martins and Stedinger, 2002)

$$
\hat{\rho}_{g_{i} g_{j}}=\frac{m_{i j}}{\sqrt{\left(m_{i j}+m_{i}\right)\left(m_{i j}+m_{j}\right)}} \operatorname{Sign}\left(\hat{\rho}_{i j}\right)\left|\hat{\rho}_{i j}\right|^{3} \text {, and }
$$

$\operatorname{Sign}\left(\hat{\rho}_{i j}\right)$ is equal to one if $\hat{\rho}_{i j}$ is positive and to minus one if $\hat{\rho}_{i j}$ is negative.

The $\operatorname{Var}\left(g_{i}\right)$ and $\operatorname{Var}\left(g_{i}\right)$ in equation 24 are approximated by (Griffis and Stedinger, 2009)

$$
\operatorname{Var}\left(g_{i}\right)=\left[\frac{6}{m_{i}}+a\right]\left[1+\left(\frac{9}{6}+b\right) G_{R, i}^{2}+\left(\frac{15}{48}+c\right) G_{R, i}^{4}\right],
$$

where

$$
\begin{gathered}
a=-\frac{17.75}{m_{i}^{2}}+\frac{50.06}{m_{i}^{3}}, \\
b=\frac{3.92}{m_{i}^{0.3}}-\frac{31.1}{m_{i}^{0.6}}+\frac{34.86}{m_{i}^{0.9}}, \text { and } \\
c=-\frac{7.31}{m_{i}^{0.59}}+\frac{45.9}{m_{i}^{1.18}}-\frac{86.5}{m_{i}^{1.77}} .
\end{gathered}
$$

Equation 19 is a simplified version of equation 22 that assumes the skew is without error. Equation 19 is provided in the WREG program to reproduce previous studies that do not use equation 22 .

\section{Performance Metrics}

The WREG program reports multiple performance metrics for multiple-linear regressions, depending upon the options (OLS, WLS, or GLS) selected. Specific metrics are reported either in the GUI or the output files of WREG.

\section{Model- and Time-Sampling Errors}

For conventional OLS and RoI regressions, the residual errors, $e_{i}$, are computed as

$$
e_{i}=\hat{y}_{i}-\hat{y}_{i r}
$$

where $\hat{y}_{i r}$ is the estimated $\hat{y}_{i}$ provided by the regression (see equation 8).

The residual mean square-error (MSE) is computed as

$$
M S E=\frac{1}{(n-k-1)} \sum_{i=1}^{n}\left(e_{i}\right)^{2},
$$

where $e_{i}$ is calculated from equation 30 .

The MSE metric does not distinguish the proportion of total error, $\varepsilon_{i}$ that is composed of model error, $\delta_{i}$, and timesampling error, $\eta_{i}$. WLS and GLS regression provide estimates of the model error variance, $\sigma_{\delta}^{2}$, which is the same as the $M S E$ only if the time sampling error variance, $\sigma_{\eta}^{2}$, is equal to zero.

For conventional regressions using WLS and GLS, WREG reports the average variance of prediction, $A V P$, as the performance metric (Tasker and Stedinger, 1986) and is given by

$$
A V P=\sigma_{\delta}^{2}+\frac{1}{n} \sum_{p=1}^{n} \mathbf{x}_{p}\left(\mathbf{X}^{T} \boldsymbol{\Lambda}^{-1} \mathbf{X}\right)^{-1} \mathbf{x}_{p}^{T}
$$

where $\mathbf{x}_{p}$ is a vector containing the values of the independent variables of the $p^{\text {th }}$ gage augmented by a value of one.

When $\hat{\mathbf{Y}}$ corresponds to the logarithm of the variable of interest, equation 32 can be reported as a percentage of the predicted value. When expressed in this way, the metric is known as the average standard error of prediction, $S_{p}$ (Aitchison and Brown, 1957, modified for use of common logarithms), and is given by

$$
S_{p}=100\left\{e^{\left[(\ln 10)^{2} A V P\right]}-1\right\}^{1 / 2} .
$$

The standard model error as a percentage of the observed value can be calculated by substituting $\sigma_{\delta}^{2}$ for $A V P$ in equation 33. WREG program reports both $S_{p}$ and the standard model error for WLS and GLS regressions.

For RoI regression, a regression is developed for each ungaged basin of interest. An overall performance metric reported by WREG program for RoI regressions using OLS, WLS, and GLS is a root mean square error, $R M S E(\%)$. This metric is similar to, but not the same as the prediction error sum of squares, PRESS, performance metric (for example, Montgomery and others, 2001). Every gage is treated in turn as an ungaged basin and a regression is developed for that site, and equations 30 and 31 are used to calculate a mean-square error value, $M S E_{R o r}$, that is used in place of $A V P$ in equation 33 to give a root mean square error of prediction expressed as a percentage of the observed value, $R M S E(\%)$, given by (Eng and others, 2005; Eng and others, 2007a)

$$
\operatorname{RMSE}(\%)=100\left\{e^{\left[(\ln 10)^{2} M S E_{\text {RoI }}\right]}-1\right\}^{1 / 2}
$$




\section{Coefficient of Determination, $\mathbf{R}^{2}, \mathbf{R}_{\text {adj }}^{2}$ and $\mathbf{R}_{\text {pseudo }}^{2}$}

A metric reported by WREG for determining the proportion of the variation in the dependent variable explained by the independent variables in OLS regressions, is the coefficient of determination, $R^{2}$, (Montgomery and others, 2001) given as

$$
R^{2}=1-\frac{S S_{r}}{S S_{T}}
$$

where

$$
\begin{aligned}
& S S_{r}=\frac{1}{n} \sum_{i=1}^{n} e_{i}^{2} \text {, and } \\
& S S_{T}=\sum_{i=1}^{n}\left(\hat{y}_{i}-\bar{y}\right)^{2},
\end{aligned}
$$

where $\bar{y}$ is the arithmetic mean of all $\hat{y}$ values,

$S S_{T}$ is the total sum of squares that is equal to the sum of the amount of variability in the observations, and

$S S_{r}$ is the residual sum of squares.

$S S_{T}$ and $S S_{r}$ values are provided as WREG output files and can be used to calculate an adjusted coefficient of determination, $R_{a d j}{ }^{2}$, given as

$$
R_{a d j}^{2}=1-\frac{S S_{r} /(n-k-1)}{S S_{T} /(n-1)} .
$$

The adjusted $R_{a d j}{ }^{2}$ adjusts for the number of independent variables used in the regression.

For WLS and GLS regressions, a more appropriate performance metric than $R^{2}$ or $R_{a d j}{ }^{2}$ is the $R_{p s e u d o}^{2}$ described by Griffis and Stedinger (2007). Unlike the $R^{2}$ metric in equation 35 and $R_{\text {adj }}{ }^{2}$ in equation $38, R_{p s u d o}^{2}$ is based on the variability in the dependent variable explained by the regression, after removing the effect of the time-sampling error. The $R_{p s e u d o}^{2}$ is given as

$$
R_{\text {pseudo }}^{2}=1-\frac{\sigma_{\delta}^{2}(k)}{\sigma_{\delta}^{2}(0)},
$$

where $\sigma_{\delta}^{2}(k)$ is the model error variance from a WLS or GLS regression with $k$ independent variables, and $\sigma_{\delta}^{2}(0)$ is the model error variance from a WLS or GLS regression with no independent variables.

For RoI regressions using OLS, WLS, or GLS, no coefficient of determination values are reported in WREG.

\section{Leverage and Influence Statistics}

The leverage metric is used to measure how far away the value of one gage's independent variables are from the centroid of values of the same variables at all other gages. This metric is reported for all gages in OLS, WLS, and GLS regressions and RoI regressions. For non-RoI regressions, leverage, $h$, for the $i^{\text {th }}$ gage is given as

$$
h_{i i}=\left[\mathbf{X}\left(\mathbf{X}^{T} \boldsymbol{\Lambda}^{-1} \mathbf{X}\right)^{-1} \mathbf{X}^{T} \boldsymbol{\Lambda}^{-1}\right]_{i i},
$$

where $\boldsymbol{\Lambda}$ is equal to either $\boldsymbol{\Lambda}_{O L S}, \boldsymbol{\Lambda}_{W L S}, \boldsymbol{\Lambda}_{G L S}$, or $\boldsymbol{\Lambda}_{G L S, \text { skew }}$.

The leverage metric for RoI regressions using either OLS, WLS, or GLS is given by (Eng and others, 2007b)

$$
\mathbf{h}_{0}^{T}=\left[\mathbf{x}_{0}\left(\mathbf{X}^{T} \boldsymbol{\Lambda}^{-1} \mathbf{X}\right)^{-1} \mathbf{X}^{T} \boldsymbol{\Lambda}^{-1}\right]
$$

where $\quad \mathbf{x}_{0}$ is a vector of independent variables at a particular ungaged basin.

Unlike equation 40, equation 41 measures the leverage that each gage record in the RoI has on the ungaged basin 0 . Leverage metrics associated with gages are considered large if these metrics exceed the criteria given by

$$
h_{\text {limit }}=\frac{C_{h}}{n} \sum_{i=1}^{n} h_{o, i},
$$

where $C_{h}$ is a constant

For conventional regression, $C_{h}$ is equal to 2 in equation 42 and reflects the observation that values twice the average can be considered as unusually large. For RoI regression, $C_{h}$ is equal to 4 (Eng and others, 2007b). A larger $C_{h}$ value for RoI regression is recommended because $\mathbf{h}_{0}{ }^{T}$ values typically exhibit greater variability, and even negative values, whereas $h_{i i}$ values are always positive. The $h_{\text {limit }}$ is reported for regressions using OLS, WLS, and GLS in the output files of the WREG program, and is also shown visually on a plot of leverage values for each gage (see sections Output Files and Leverage Values Versus

\section{Observations)}

The leverage metrics in equations 40 and 41 identify gages whose independent variables are unusual. Such unusual gages may or may not have any significant impact on the estimated regression parameters in equations 9,11 , and 18 . An influence metric, such as Cook's D (Cook, 1977), indicates whether a gage had a large influence on the estimated regression parameter values. A generalized Cook's D value for the $i^{\text {th }}$ gage is

$$
\text { Cook's } D_{i}=\frac{e_{i}^{2} L_{i i}}{v\left(\Lambda_{i i}-L_{i i}\right)^{2}},
$$

where $v$ is the dimension of $\boldsymbol{\beta}$,

$\Lambda_{i i}$ is the $i^{\text {th }}$ main diagonal of the $\boldsymbol{\Lambda}$ covariance matrix, and

$L_{i i}$ is the $i^{\text {th }}$ main diagonal of $\mathbf{X}\left(\mathbf{X}^{T} \Lambda^{-1} \mathbf{X}\right)^{-1} \mathbf{X}^{T}$ (Tasker and Stedinger, 1989). 
For regressions, a gage that has caused large influence is identified if Cook's D exceeds the limit given by

$$
D_{\text {limit }}=\left(\frac{4}{n}\right) \text {. }
$$

The Cook's D limit calculated using equation 44 is reported in the WREG output files (see section Output Files), and visually on a plot of influence values (see section Influence Values Versus Observation).

\section{Significance of Regression Parameters}

Regression parameters are tested for significance by WREG for regressions not using RoI regions. The null hypothesis is generally that the regression parameter is equal to zero, and the alternative hypothesis is that this parameter is not equal to zero. If the null hypothesis is not rejected at some predefined level of significance, such as $5 \%$, then the associated independent variable is removed from the regression. For regressions, the test statistic that is used to evaluate the null hypothesis is the $T$ value statistic given as

$$
T \text { value }=\frac{\beta_{k}}{\left(\operatorname{Var} \beta_{k}\right)^{1 / 2}},
$$

where $\left(\operatorname{Var} \beta_{k}\right)$ is the covariance value of $\beta_{k}$, and is given as

$$
\operatorname{Var} \beta_{k}=\left(\mathbf{X}^{T} \boldsymbol{\Lambda}^{-1} \mathbf{X}\right)_{k k}^{-1}
$$

The $T$ value statistic in equation 45 is assumed to follow a Student's t distribution, so probabilities or "p-values" can be calculated. If the critical level of significance is set to $5 \%$ (0.05), p-values associated with the calculated $T$ value statistic from equation 45 that exceed 0.05 result in acceptance of the null hypothesis. In this case, the regression parameter is not considered significant. In WREG, coefficients that are not significant at the $5 \%$ significance level are flagged (see section Regression Summary).

\section{Definition of Regions}

The region formed by a collection of gages can influence the regression model and the significance of the results. For conventional regressions, the WREG program uses all gages that are input by the user to develop regressions using either OLS, WLS, or GLS. If a subset of gages from a larger data set is desired by the user, input files to WREG should be modified to reflect the smaller subset.

For RoI regressions, a select subset from all available gages is formed for every ungaged basin where an estimate is desired. To use the RoI regression feature in WREG, a user would input all possible gages of interest, even though some gages might not be used in each RoI regression. Three approaches for defining hydrologic similarity among basins are available with WREG: independent or predictor-variable space RoI (PRoI) (for example, Burns, 1990), geographic space RoI (GRoI), and a combination of predictor-variable and geographic spaces called hybrid RoI (HRoI) developed by Eng and others (2007a).

For the GRoI option in WREG, a region of influence is formed using the $n$ gages that are geographically the closest to the ungaged basin. In general, $n$ is specified and is the same for every regression. The PRoI option in WREG is similar, but forms a region using the $n$ closest gages in independent-variable space rather than geographic space. Thus, the region is comprised of gages whose independent variables have values that are the most similar to the ungaged site. Distance in independent-variable space from the ungaged basin to the $i^{\text {th }}$ gage, $R_{i}$, is defined in a Euclidean sense as (for example, Burns, 1990)

$$
R_{i}=\left[\left(\frac{x_{1}-x_{1 i}}{s_{x_{1}}}\right)^{2}+\left(\frac{x_{2}-x_{2 i}}{s_{x_{2}}}\right)^{2}+\cdots+\left(\frac{x_{k}-x_{k i}}{s_{x_{k}}}\right)^{2}\right]^{1 / 2},
$$

where

$$
\begin{aligned}
s_{x_{1}}, s_{x_{2}}, \text { and } s_{x_{k}} \text { are the sample standard deviations } \\
\text { of } x_{1}, x_{2} \text {, and } x_{k} \text {, respectively } \\
\text { (computed from data from the } \\
\text { entire study region). }
\end{aligned}
$$

The HRoI approach uses a region of influence of the $n$ closest gages in independent-variable space chosen from a subset of all gages having a geographic distance less than $D$ from the ungaged basin. However, if fewer than $n$ gages are available within the distance $D$ of a given ungaged basin, then the limit $D$ is ignored, HRoI reverts to GRoI and the $n$ geographically closest gages are used. Thus, in the limit as $D$ approaches zero, HRoI reduces to GRoI, and in the limit as $D$ becomes arbitrarily large, HRoI reduces to PRoI (Eng and others, 2007a).

The user must determine the optimal $D$ and $n$ values. This determination can be accomplished by splitting the dataset into three equally sized subsets. Two of the three subsets are combined and used in an optimization step to calculate RMSE values for various values of $n$ and $D$ for HRoI regionalization. The same subsets are used to calculate $R M S E$ values for various values of $n$ for both PRoI and GRoI. The lowest resulting values of $R M S E$ and the corresponding values of $n$ and $D$ for HRoI and of just $n$ for PRoI and GRoI are noted. The third subset is then used to evaluate model performance, by calculating the $R M S E$ value associated with the optimal $n$ and $D$ determined in the previous step. All possible combinations of three subsets for this optimization-evaluation procedure are employed, and an overall RMSE value is then computed as the root mean-square value of the three individual subset values (Eng and others, 2005; Eng and others, 2007a). 


\section{Use of the WREG Program}

The remainder of this report provides details on how to use the Weighted-Multiple-Linear Regression Program (WREG). It can be used to set up, run, and evaluate a multiple-linear regression. As described in previous sections, the methods used by the program have been customized for use in the regionalization of streamflow characteristics. Many of the default methods may not be suitable for other regression problems.

The program is driven by a graphical user interface that leads the user through the process of setting up a regression. A number of input files are required, and detailed output is available in text files generated by WREG.

Notice.-MATLAB ${ }^{\circledR} .{ }^{\circledR} 1984-2007$ The MathWorks, Inc. was used to develop the graphical user interface and source code for WREG. The licensee's rights to deployment of WREG are governed by the license agreement between licensee and MathWorks, and licensee may not modify or remove any license agreement file that is included with the MCR libraries. Installation of the application denotes acceptance of the terms of the license specified in the file named license.txt in the folder WREGv1 included with this manual.

\section{Program Requirements}

- Windows operating system.

- Approximately $400 \mathrm{MB}$ of free disk space.

\section{Installation}

1. Unzip the distribution file (WREGv1.zip) and extract it to the directory of your choosing. There should be four files-MCRInstaller.exe, WREGv1.exe, WREGv1.ctf, and license.txt—and two folders-WREG_Source_Code and Sample_Files.

2. Run the program MCRInstaller.exe. This program installs MATLAB Component Runtime, software that allows the WREG executable program to run. The installation program leads you through the process with multiple GUI windows and may take several minutes to complete. Administrator privileges are required.

3. WREGv1.exe and WREGv1.ctf should be copied to another folder that contains input files and the program can be executed from that location. For example, copying the files into the folder Sample_Files will allow execution of the program using the sample input files. Alternatively, input files can be copied to the directory in which WREGv1.exe and WREGv1.ctf were installed.

4. WREGv1.exe is the program executable file and it is now ready to run. WREGv1.ctf is a required file that must be located in the same working directory as WREGv1. exe. After WREG is run for the first time, another folder, WREGv1_mcr, will be created in the working directory. It contains additional files for running WREG. These files should not be changed. (If a new version of WREG is provided, the files WREGv1.exe and WREGv1.ctf and the folder WREGv1_mcr should all be deleted from the working directory. The new WREG.exe and WREG.ctf should be placed in the directory. A new WREG_mor folder will be created the first time WREG is executed.)

5. Double-click on WREGv1.exe to start WREG.

\section{Input Files}

The input files are listed in table 1 with a brief description. WREG automatically reads these files to set up the regression. Input files that are required for a regression analysis must be located in the same working directory as the WREGv1.exe executable file. As noted in table 1, some input files are always required for the program to run. Others are required only for certain WREG options, as noted in table 1. All input files are text files, and all fields within them are tab-delimited. The input files can be created, viewed, and edited in a spreadsheet program, such as Microsoft Excel, and then saved as a tab-delimited file. They can also be created, viewed, and edited using a text editor. Note that some text editors may not display the input files in an easy-to-read format, with properly aligned columns. A detailed description of each file's contents and format follows.

Table 1. WREG input files.

\begin{tabular}{|c|c|c|}
\hline File name & Description & WREG requirements \\
\hline SiteInfo.txt & $\begin{array}{l}\text { Site information and basin characteristics to be used in the } \\
\text { regression (the independent variables) }\end{array}$ & Always required. \\
\hline FlowChar.txt & $\begin{array}{l}\text { Flow characteristics to be used in the regression (the de- } \\
\text { pendent variables) }\end{array}$ & Always required. \\
\hline LP3G.txt & Skew for Log-Pearson Type III distribution & Always required. \\
\hline LP3K.txt & K for Log-Pearson Type III distribution & Always required. \\
\hline LP3s.txt & Standard deviation for Log-Pearson Type III distribution & Always required. \\
\hline USGS\#\#\#\#\#\#\#\#.txt & Annual time series of flow at streamflow-gaging stations & $\begin{array}{l}\text { Required only when using the GLS option. When needed, } \\
\text { one file is required for each streamflow-gaging station } \\
\text { listed in SiteInfo.txt. }\end{array}$ \\
\hline
\end{tabular}


The examples are based on the input files in the Sample Files directory distributed with WREG and use peak-flow statistics and basin attributes for streamflow-gaging stations in Iowa.

\section{Sitelnfo.txt}

This input file contains the independent variables that may be used in the regression. An example file is shown in figure 1. All fields are tab-delimited. The first row contains header information describing the contents of each column. Information about each streamflow-gaging station is listed in the rows below the header.

The first eight columns are required:

1. Station ID: The USGS identifier for each streamflowgaging station.

2. Lat: Latitude of the streamflow-gaging station (or centroid of the watershed). The latitude and longitude are used to approximate the distance between streamflow-gaging stations in the GLS option. Latitude should be entered in decimal degrees (positive).

3. Long: Longitude of the streamflow-gaging station (or centroid of the watershed). Longitude should be entered in decimal degrees (either positive or negative).

4. No. Annual Series: The number of years of record available at the streamflow-gaging station, and used to estimate flow characteristics at the station. This information is used by WREG to assign weights to each streamflow gaging station. In general, only complete years of record should be used to generate flow characteristics.

5. Zero-1;NonZero-2: Flow characteristics (used for the dependent variable in a regression) will sometimes equal zero at a streamflow-gaging station. This field should show a 1 if the dependent variable for a station is equal to zero, and 2 if not. This field is not currently used by the WREG, but a value must be provided. The field is intended to facilitate addition of logistic regression to future versions of WREG.

6. FreqZero: The number of instances in which the annualtime series values equals zero. For example, if the regression will estimate the $Q_{7,10}$, the number of years in which the 7-day minimum flow was equal to zero should be entered here. ${ }^{1}$ Note that these values may need to change if a different flow statistic is used as the response variable. This field is not currently used by WREG, but a value must be provided. It is included to facilitate addition of logistic regression to future versions of WREG.

7. Regional Skew: This field is the value of the regional skew used to calculate a peak-flow frequency statistic. If a regional skew is not applicable, then a dummy value, such as -99.99 , needs to be entered. This field is only used when forming a WLS or GLS regression, but a value must always be supplied.

8. Cont-1:PR-2: This field should show a 1 if the station is a continuous streamflow-gaging station, or a 2 if it is a partial-record site. For peak-flow studies, crest-stage gages should be treated like streamflow-gaging stations. In lowflow studies, partial-record sites (or miscellaneous sites) are sometimes used to supplement continuous-record stations. At the partial-record sites, only sporadic measurements are made. Estimation of flow characteristics at partial-record sites requires specialized techniques. The resulting estimates of flow characteristics at partial-record sites have larger uncertainty than estimates at continuous-record stations.

${ }^{1}$ The $Q_{7,10}$ is the lowest stream flow for 7 consecutive days that would be expected to occur on average once in 10 years. It is estimated using an annualtime series of the minimum 7-day flows.

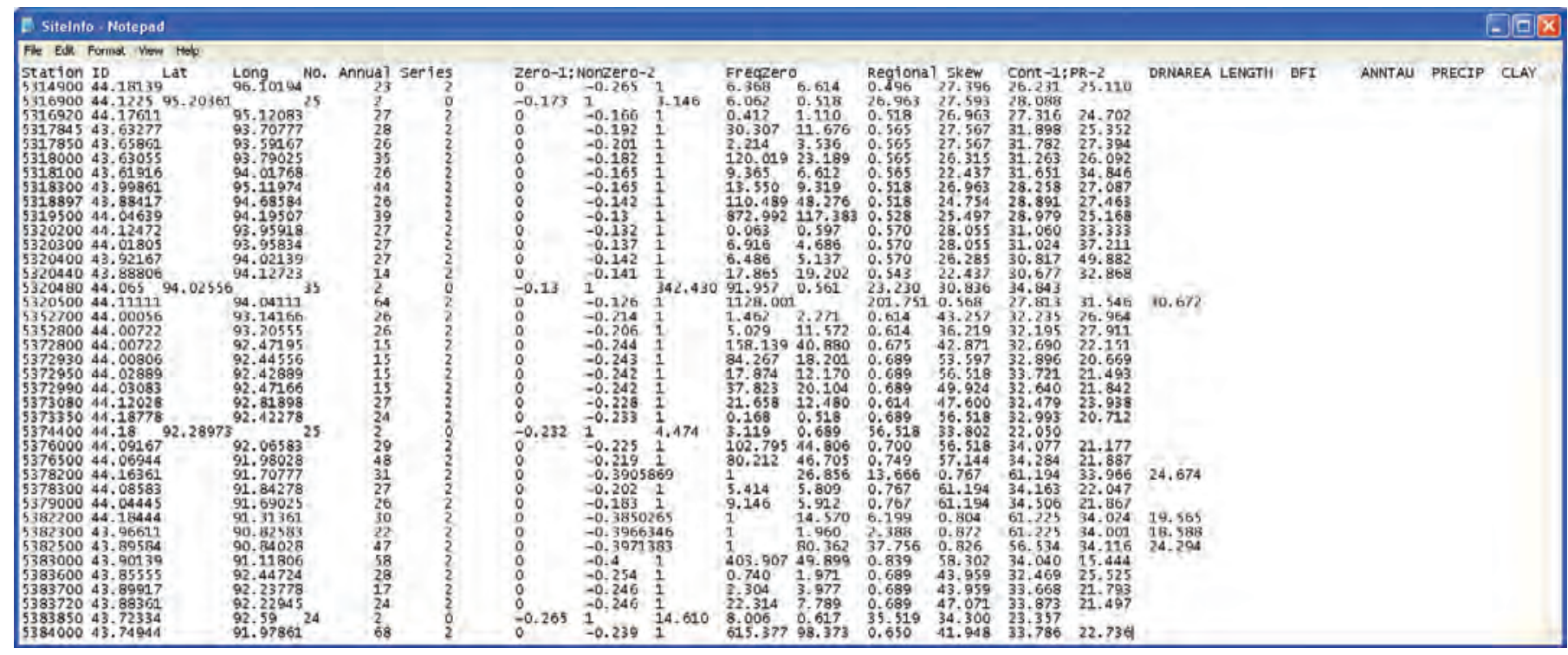

Figure 1. Example of input file Sitelnfo.txt in text tab-delimited format, as shown in $A$, the Notepad text editor and $B$ (next page), Microsoft Excel. 


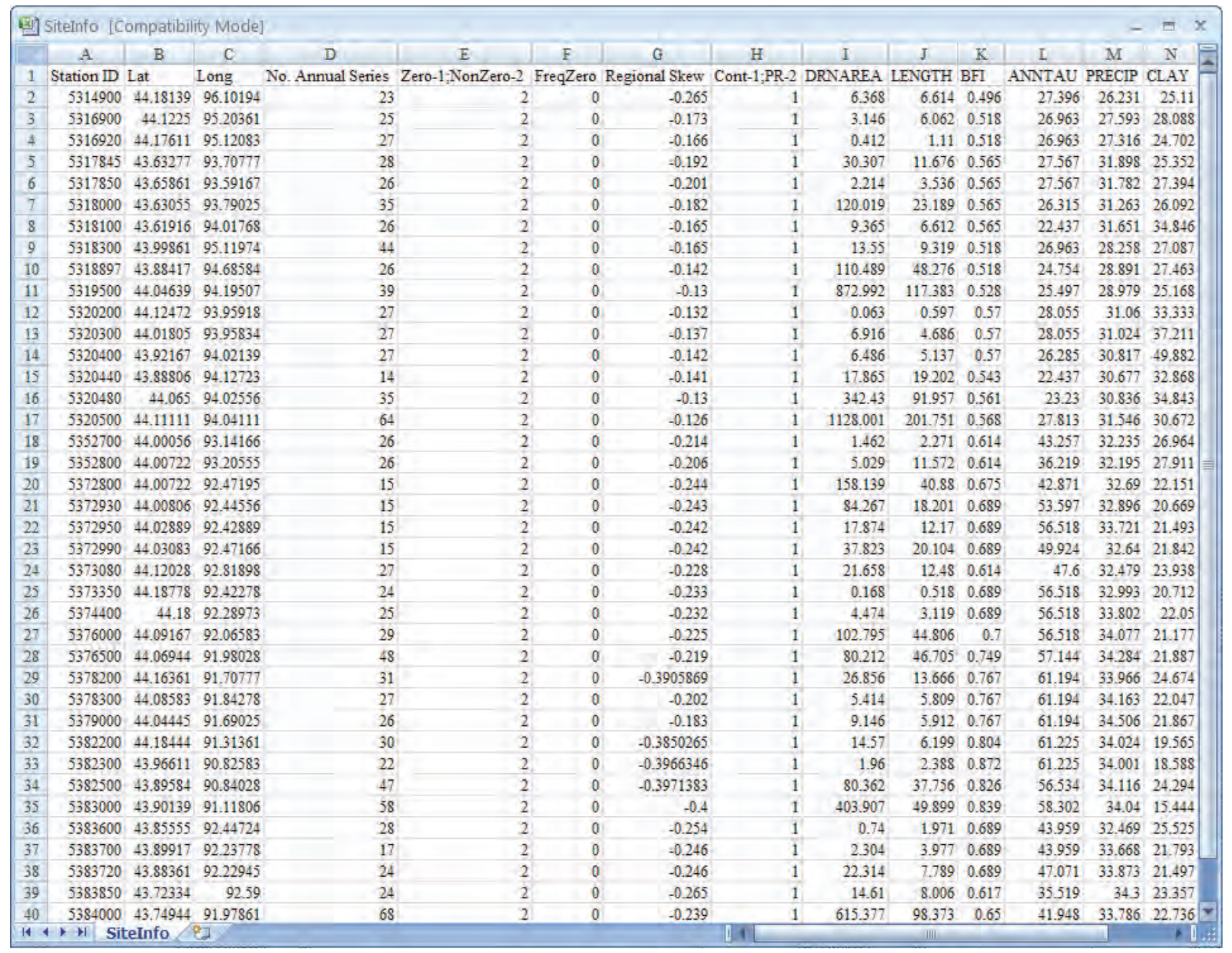

Figure 1. (continued)

9. In the columns following these required entries, independent variables (basin characteristics) should be entered. The headers should be descriptive, as they will be displayed by WREG for selection of independent variables. For display purposes, a maximum of 11 characters is recommended.

Streamflow-gaging stations must be listed in ascending alphanumeric order (by USGS station identifier numbers) in this file and all others in which each row contains information for one station (FlowChar.txt, LP3G.txt, LP3K.txt, LP3s.txt). The order in which the gaging stations are listed should be the same as the order in which the USGS\#\#\#\#\#\#\#\#.txt files are shown in Windows Explorer when sorted by name.

\section{FlowChar.txt}

This file contains the dependent variables that may be selected for use in the regression. An example is shown in figure 2. All fields are tab-delimited. The first row contains header information describing the contents of each column. The first column, Station ID, is required and entries should be identical to those in column 1 of the SiteInfo.txt file. Note that the program requires all streamflow-gaging stations to be entered in the same order in both files.

Following the Station ID column, the remaining columns are used to define flow characteristics. The names used in the header should be descriptive, as they will later be used by the WREG to solicit user input. For display purposes, a maximum of 11 characters is recommended.

\section{LP3G.txt}

This file contains the skew value for each streamflow-gaging station that was used when fitting the log-Pearson Type III distribution. An example is shown in figure 3. All fields are tabdelimited. The first row contains header information describing the contents of each column. The first column, Station ID, is 


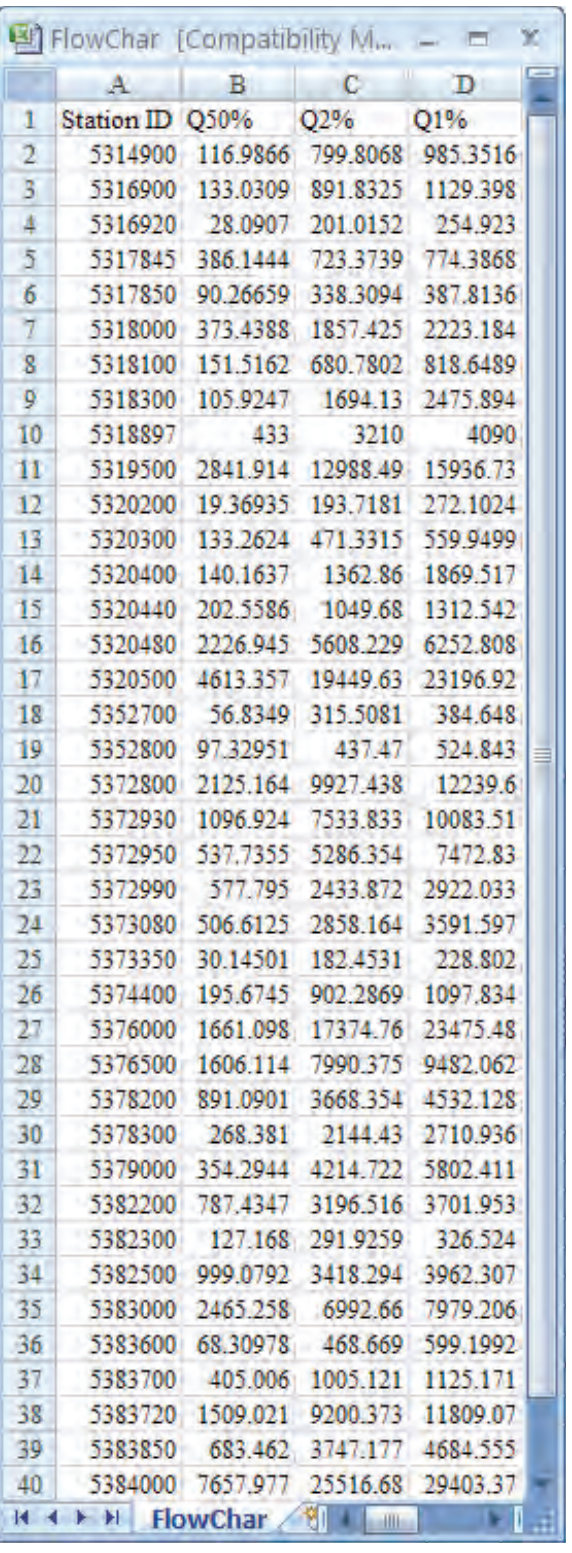

Figure 2. Example of input file FlowChar. txt in text tab-delimited format, as shown in Microsoft Excel.

required and entries must match those in column 1 of the SiteInfo.txt and FlowChar.txt files. Again, the program requires all streamflow-gaging stations to be entered in the same order in both files, in ascending alphanumeric gage site order.

Following the Station ID column, skew values for each of the frequency statistics listed in FlowChar.txt should be entered. These columns should correspond to those used in FlowChar.txt (for example, if column 2 of FlowChar.txt contains a peak for statistic, the skew value in column 2 of LP3G.txt should be

\begin{tabular}{|c|c|c|c|c|c|}
\hline \multicolumn{4}{|c|}{ 질] LP3G [Compatibility Mlode] } & \multicolumn{2}{|c|}{$-\square x$} \\
\hline & A & B & C & D & \\
\hline 1 & Station ID & Skew $50 \%$ & Skew $2 \%$ & Skew $1 \%$ & \\
\hline 2 & 5314900 & -0.4378513 & -0.4378513 & -0.4378513 & \\
\hline 3 & 5316900 & -0.1628717 & -0.1628717 & -0.1628717 & \\
\hline 4 & 5316920 & -0.224812 & -0.224812 & -0.224812 & \\
\hline 5 & 5317845 & -0.4373209 & -0.4373209 & -0.4373209 & \\
\hline 6 & 5317850 & -0.5238652 & -0.5238652 & -0.5238652 & \\
\hline 7 & 5318000 & -0.3778404 & -0.3778404 & -0.3778404 & \\
\hline 8 & 5318100 & -0.1882706 & -0.1882706 & -0.1882706 & \\
\hline 9 & 5318300 & 157 & 813257 & & \\
\hline 10 & 5318897 & -0.2199 & -0.2199 & -0.2199 & \\
\hline 11 & 5319500 & 0.0368123 & 0.0368123 & 0.0368123 & \\
\hline 12 & 5320200 & 0.301714 & 0.301714 & 0.301714 & \\
\hline 13 & 5320300 & 0. & 0.071 & & \\
\hline 14 & 5320400 & 0.125 & 0.123498 & 98 & \\
\hline 15 & 5320440 & 0.06 & 0.060 & 0.060 & \\
\hline 16 & 5320480 & -0.2773506 & -0.2773506 & -0.2773506 & \\
\hline 17 & 5320500 & -0.1934 & -0.1934676 & -0.1 & \\
\hline 18 & 5352700 & -0.3 & -0.3161195 & $-0,3$ & \\
\hline 19 & 5352800 & -0.2 & -0.2169663 & 663 & \\
\hline 20 & 5372800 & 0060 & 00 G & & \\
\hline 21 & 5372 & & & & \\
\hline 22 & 5372950 & 0.3 & 0.38 & 335 & \\
\hline 23 & 5372990 & -0.1072303 & -0.1072303 & -0.1072303 & \\
\hline 24 & 5373080 & -0.01383939 & -0.01383939 & -0.01383939 & \\
\hline 25 & 5373350 & -0.1332477 & -0.1332477 & -0.13 & \\
\hline 26 & 5374400 & -0.08422817 & -0.08422817 & -0.0842 & \\
\hline 27 & 5376000 & -0.08696695 & -0.08696695 & -0.08696695 & \\
\hline 28 & 5376500 & -0.4687821 & -0.4687821 & $-0,4687821$ & \\
\hline 29 & 5378200 & 0.341917 & 0.341917 & 0.341917 & \\
\hline 30 & 5378300 & -0.3649173 & -0.3649173 & -0.3649173 & \\
\hline 31 & 5379000 & -0.06969751 & -0.06969751 & -0.06969751 & \\
\hline 32 & 5382200 & -0.5004891 & -0.5004891 & -0.5004891 & \\
\hline 33 & 5382300 & 0.0400738 & 0.0400738 & 0.0400738 & \\
\hline 34 & 5382500 & -0.2367817 & -0.2367817 & -0.2367817 & \\
\hline 35 & 5383000 & -0.117111 & -0.117111 & -0.117111 & \\
\hline 36 & 5383600 & -0.09854396 & -0.09854396 & -0.09854396 & \\
\hline 37 & 5383700 & -0.1627242 & -0.1627242 & -0.1627242 & \\
\hline 38 & 5383720 & 0.105583 & 0.105583 & 0.105583 & \\
\hline 39 & 5383850 & -0.02941165 & -0.02941165 & -0.02941165 & \\
\hline 40 & 5384000 & -0.2773225 & -0.2773225 & -0.2773225 & \\
\hline 14. & $\rightarrow \quad L P$ & 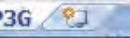 & IIILIIII & ? & \\
\hline
\end{tabular}

Figure 3. Example of input file LP3G.txt as shown in Microsoft Excel. Note that the skew values entered for each streamflow gage are the same, since each flow statistic $(02,050$, and 0100$)$ is based on the same annual-peak-flow series.

that for the annual peak flowtime series). Each statistic in FlowChar.txt must have a corresponding skew value. Note that if each statistic is based on the same annual series, the skews will be identical. If the statistic is not a frequency statistic and no skew was used in its computation, a dummy value of -99.99 may be used in the LP3G.txt file. For peak-flow studies, the weighted skew (equation 16) should be entered in LP3G.txt if it the weighted skew was used when fitting the log-Pearson Type III distribution. For other flow characteristics where a regional skew is not calculated, the at-site skew values, $g$, should be used. Information in this file is used by the WLS and GLS options.

\section{LP3K.txt}

This file contains the log-Pearson Type III distribution standard deviate, $K$, values ( $K$ values for a given exceedance probability and skew are tabulated in Bulletin 17B). An example is shown in figure 4. All fields are tab-delimited. The first row contains header information describing the contents of each column. The first column, Station ID, is required and must match the entries in column 1 of the SiteInfo.txt and FlowChar.txt files. Again, the program requires all streamflow-gaging stations to be entered in the same order in both files.

Following the Station ID column, $K$ values for each of the frequency statistics listed in FlowChar. txt should be entered. These columns

\begin{tabular}{|c|c|c|c|c|c|}
\hline \multicolumn{4}{|c|}{ 빨] LPSK [Compatibility Mlode] } & - & $x$ \\
\hline & A & B: & \multirow{2}{*}{${ }_{\mathrm{K}-2 \%}^{\mathrm{C}}$} & D & \\
\hline 1 & Station ID & $\mathrm{K}-50 \%$ & & $\mathrm{~K}-1 \%$ & \\
\hline 2 & 5314900 & 0.072767413 & 1.812297037 & 2.001088134 & \\
\hline 3 & 5316900 & 0.027070618 & 1.965394581 & 2.205978284 & \\
\hline 4 & 5316920 & 0.037384795 & 1.93130667 & 2.15995156 & \\
\hline 5 & 5317845 & 0.072680595 & 1.812593884 & 2.001480333 & \\
\hline 6 & 5317850 & 0.08694837 & 1.763634163 & 1.936943252 & \\
\hline 7 & 5318000 & 0.062842982 & 1.846054561 & 2.045862906 & \\
\hline 8 & 5318100 & 0.031297102 & 1.951447779 & 2.187118374 & \\
\hline 9 & 5318300 & -0.013515765 & 2.097095217 & 2.385975852 & \\
\hline 10 & 5318897 & 0.083117378 & 4.218179812 & 4.718266673 & \\
\hline 11 & 5319500 & -0.006119623 & 2.073431829 & 2.353375962 & \\
\hline 12 & 5320200 & -0.05021578 & 2.21168206 & 2.545434209 & \\
\hline 13 & 5320300 & -0.011904809 & 2.091969296 & 2.378903582 & \\
\hline 14 & 5320400 & -0.020526419 & 2.119353595 & 2.416735811 & \\
\hline 15 & 5320440 & -0.010102404 & 2.086201257 & 2.370956573 & \\
\hline 16 & 5320480 & 0.046162668 & 1.90218558 & 2.12081518 & \\
\hline 17 & 5320500 & 0.032161704 & 1.948586188 & 2.183254439 & \\
\hline 18 & 5352700 & 0.052610758 & 1.880608501 & 2.091927142 & \\
\hline 19 & 5352800 & 0.036077556 & 1.935636761 & 2.165786039 & \\
\hline 20 & 5372800 & -0.010074929 & 2.086119148 & 2.370843197 & \\
\hline 21 & 5372930 & -0.063541133 & 2.252341203 & $2.60268420 \mathrm{~S}$ & \\
\hline 22 & 5372950 & -0.064165022 & 2.25423346 & 2.605358363 & \\
\hline 23 & 5372990 & 0.017820983 & 1.995796321 & 2.247229884 & \\
\hline 24 & 5373080 & 0.002301058 & 2.046323439 & 2.316172943 & \\
\hline 25 & 5373350 & 0.022148351 & 1.981612222 & 2.227965038 & \\
\hline 26 & 5374400 & 0.013997827 & 2.008296887 & 2.264241009 & \\
\hline 27 & 5376000 & 0.0144538 & 2.006811996 & 2.262218142 & \\
\hline 28 & 5376500 & 0.077873222 & 1.794821396 & 1.977990323 & \\
\hline 29 & 5378200 & -0.056892064 & 2.23210384 & 2.574143948 & \\
\hline 30 & 5378300 & 0.060701594 & 1.853302285 & 2.055504884 & \\
\hline 31 & 5379000 & 0.011581799 & 2.016175991 & 2.274978075 & \\
\hline 32 & 5382200 & 0.083100798 & 1.776882643 & 1.954355253 & \\
\hline 33 & 5382300 & -0.006657815 & 2.075179274 & 2.355775512 & \\
\hline 34 & 5382500 & 0.039378013 & 1.924685774 & 2.151041177 & \\
\hline 35 & 5383000 & 0.019463871 & 1.990412151 & 2.2399138 & \\
\hline 36 & 5383600 & 0.016378007 & 2.000520072 & 2.253655043 & \\
\hline 37 & 5383700 & 0.027044003 & 1.965471533 & 2.206083685 & \\
\hline 38 & 5383720 & -0.017547655 & 2.109914574 & 2.403680662 & \\
\hline 39 & 5383850 & 0.004887033 & 2.037944157 & 2.304705099 & \\
\hline 40 & 5384000 & 0.046157329 & 1.902207429 & 2.120841931 & \\
\hline it & 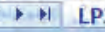 & $3 K$ & 11. & $\sigma_{1}$ & \\
\hline
\end{tabular}

Figure 4. Example of input file LP3K.txt as shown in Microsoft Excel. 
should correspond to those used in FlowChar.txt (that is, if column 2 of FlowChar.txt contains the $Q_{7,10}$, the $K$ value in column 2 of LP3K.txt should be that for the 7-day annual-time series). Each statistic in FlowChar.txt must have a corresponding $K$ value. If the statistic is not a frequency statistic, a dummy value of -99.99 may be used in the LP3K.txt file. Information in this file is used by the WLS and GLS options.

\section{LP3s.txt}

This file contains the standard deviation, $\sigma$, of the annual-time series that was fit to the log-Pearson Type III

\begin{tabular}{|c|c|c|c|c|c|}
\hline \multicolumn{4}{|c|}{ 빌] LP35 [Compatibility Mode] } & \multicolumn{2}{|c|}{$-a x$} \\
\hline & A & B & C & D & \\
\hline 1 & Station ID & $s-50 \%$ & $s-2 \%$ & $s-1 \%$ & \\
\hline 2 & 5314900 & 0.479928 & 0.479928 & 0.479928 & \\
\hline 3 & 5316900 & 0.426312 & 0.426312 & 0.426312 & \\
\hline 4 & 5316920 & 0.451268 & 0.451268 & 0.451268 & \\
\hline 5 & 5317845 & 0.156682 & 0.156682 & 0.156682 & \\
\hline 6 & 5317850 & 0.342215 & 0.342215 & 0.342215 & \\
\hline 7 & 5318000 & 0.390695 & 0.390695 & 0.390695 & \\
\hline 8 & 5318100 & 0.339842 & 0.339842 & 0.339842 & \\
\hline 9 & 5318300 & 0.570427 & 0.570427 & 0.570427 & \\
\hline 10 & 5318897 & 0.2104 & 0.2104 & 0.2104 & \\
\hline 11 & 5319500 & 0.317351 & 0.317351 & 0.317351 & \\
\hline 12 & 5320200 & 0.442131 & 0.442131 & 0.442131 & \\
\hline 13 & 5320300 & 0.260766 & 0.260766 & 0.260766 & \\
\hline 14 & 5320400 & 0.461622 & 0.461622 & 0.461622 & \\
\hline 15 & 5320440 & 0.340841 & 0.340841 & 0.340841 & \\
\hline 16 & 5320480 & 0.216116 & 0.216116 & 0.216116 & \\
\hline 17 & 5320500 & 0.326073 & 0.326073 & 0.326073 & \\
\hline 18 & 5352700 & 0.407219 & 0.407219 & 0.407219 & \\
\hline 19 & 5352800 & $0.34360 \mathrm{~s}$ & 0.343608 & 0.343608 & \\
\hline 20 & 5372800 & 0.319362 & 0.319362 & 0.319362 & \\
\hline 21 & 5372930 & 0.361348 & 0.361348 & 0.361348 & \\
\hline 22 & 5372950 & 0.428135 & 0.428135 & 0.428135 & \\
\hline 23 & 5372990 & 0.315739 & 0.315739 & 0.315739 & \\
\hline 24 & 5373080 & 0.367614 & 0.367614 & 0.367614 & \\
\hline 25 & 5373350 & 0.399056 & 0.399056 & 0.399056 & \\
\hline 26 & 5374400 & 0.332854 & 0.332854 & 0.332854 & \\
\hline 27 & 5376000 & 0.511717 & 0.511717 & 0.511717 & \\
\hline 28 & 5376500 & 0.405831 & 0.405831 & 0.405831 & \\
\hline 29 & 5378200 & 0.26848 & 0.26848 & 0.26848 & \\
\hline 30 & 5378300 & 0.503492 & 0.503492 & 0.503492 & \\
\hline 31 & 5379000 & 0.53647 & 0.53647 & 0.53647 & \\
\hline 32 & 5382200 & 0.359233 & 0.359233 & 0.359233 & \\
\hline 33 & 5382300 & 0.173354 & 0.173354 & 0.173354 & \\
\hline 34 & 5382500 & 0.283354 & 0.283354 & 0.283354 & \\
\hline 35 & 5383000 & 0.229727 & 0.229727 & 0.229727 & \\
\hline 36 & 5383600 & 0.421534 & 0.421534 & 0.421534 & \\
\hline 37 & 5383700 & 0.203648 & 0.203648 & 0.203648 & \\
\hline 38 & 5383720 & 0.369036 & 0.369036 & 0.369036 & \\
\hline 39 & 5383850 & 0.363487 & 0.363487 & 0.363487 & \\
\hline 40 & 5384000 & 0.281625 & 0.281625 & 0.281625 & \\
\hline 14 & $\leftrightarrow \quad$ LP & 35,8 & W1 & +1 & \\
\hline
\end{tabular}

Figure 5. Example of input file LP3s.txt as shown in Microsoft Excel. distribution. An example is shown in figure 5. All fields are tab-delimited. The first row contains header information describing the contents of each column. The first column, Station ID, is required and must match the entries in column 1 of the SiteInfo.txt and FlowChar.txt files. Again, the program requires all streamflow-gaging stations to be entered in the same order in both files.

Following the Station ID column, $\sigma$ values for each of the frequency statistics listed in FlowChar.txt should be entered. These columns should correspond to those used in FlowChar.txt (that is, if column 2 of FlowChar.txt contains the $Q_{7.10}$, the $\sigma$ value in column 2 of LP3K.txt should be that for the 7-day annual-time series). Each statistic in FlowChar.txt must have a corresponding value for $\sigma$. If the statistic is not a frequency statistic and $\sigma$ is not used in its computation, a dummy value of -99.99 may be used in the LP3s.txt file. Information in this file is used by the WLS and GLS options.

\section{UserWLS.txt}

A user-defined weighting matrix can be specified in UserWLS.txt. This file contains no header information and simply contains the desired values of the $\boldsymbol{\Lambda}$ matrix (for example, equations 10,12 , and 19). The $\boldsymbol{\Lambda}$ matrix is a square matrix containing $n$ rows and $n$ columns, where $n$ is the number of sites used in the regression analysis. WREG inverts this matrix to assign weights to each station used in the analysis. When using WLS, only the main diagonal of this matrix contains nonzero values. In the UserWLS.txt file, observations that have smaller variance and are thus considered to be more reliable should be given smaller values. When the matrix is inverted by WREG, these observations will be given larger weight. Observations with large variance (for example, at partial-record sites) would be considered less reliable and should be assigned larger values. When the matrix is inverted by WREG, these observations will be given smaller weight. For a GLS regression,

\begin{tabular}{|c|c|c|c|c|c|c|c|c|c|c|c|c|c|c|}
\hline$\pi$ & A & B & C & D & E & $F$ & G & $\mathrm{H}$ & I & $\mathrm{J}$ & $\mathrm{K}$ & I & M & 들 \\
\hline 1 & 1.122548 & 0 & 0 & 0 & 0 & 0 & 0 & 0 & 0 & 0 & 0 & 0 & 0 & 0 \\
\hline 2 & $\overline{0}$ & 1.032744 & 0 & 0 & 0 & 0 & 0 & 0 & 0 & 0 & 0 & 0 & 0 & 0 \\
\hline 3 & 0 & 0 & 0.956244 & 0 & 0 & 0 & 0 & 0 & 0 & 0 & 0 & 0 & 0 & 0 \\
\hline 4 & 0 & 0 & 0 & 0.922093 & 0 & 0 & 0 & 0 & 0 & 0 & 0 & 0 & 0 & 0 \\
\hline 5 & 0 & 0 & 0 & 0 & 0.993023 & 0 & 0 & 0 & 0 & 0 & 0 & 0 & 0 & 0 \\
\hline 6 & 0 & 0 & 0 & 0 & 0 & 0.737674 & 0 & 0 & 0 & 0 & 0 & 0 & 0 & 0 \\
\hline 7 & 0 & 0 & 0 & 0 & 0 & 0 & 0.993023 & 0 & 0 & 0 & 0 & 0 & 0 & 0 \\
\hline 8 & 0 & 0 & 0 & 0 & 0 & 0 & 0 & 0.586786 & 0 & 0 & 0 & 0 & 0 & 0 \\
\hline 9 & 0 & 0 & 0 & 0 & 0 & 0 & 0 & 0 & 0.993023 & 0 & 0 & 0 & 0 & 0 \\
\hline 10 & 0 & 0 & 0 & 0 & 0 & 0 & 0 & 0 & 0 & 0.662015 & 0 & 0 & 0 & 0 \\
\hline 11 & $n$ & 0 & 0 & 0 & 0 & a & 0 & 0 & n & 0 & 0956244 & 0 & 0 & 0 \\
\hline 12 & 0 & 0 & 0 & 0 & 0 & 0 & 0 & 0 & 0 & 0 & 0 & 0.956244 & 0 & 0 \\
\hline 13 & 0 & 0 & 0 & 0 & 0 & 0 & 0 & 0 & 0 & 0 & 0 & 0 & 0.956244 & \\
\hline 14 & 0 & 0 & 0 & 0 & 0 & 0 & 0 & 0 & 0 & 0 & 0 & 0 & 0 & 0 \\
\hline 15 & 0 & 0 & 0 & 0 & 0 & 0 & 0 & 0 & 0 & 0 & 0 & 0 & 0 & 0 \\
\hline 16 & 0 & 0 & 0 & 0 & 0 & 0 & 0 & 0 & 0 & 0 & 0 & 0 & 0 & 0 \\
\hline 17 & 0 & 0 & 0 & 0 & 0 & 0 & 0 & 0 & 0 & 0 & 0 & 0 & 0 & 0 \\
\hline 18 & 0 & 0 & 0 & 0 & 0 & 0 & 0 & 0 & 0 & 0 & 0 & 0 & 0 & 0 \\
\hline 19 & 0 & 0 & 0 & 0 & 0 & 0 & 0 & 0 & 0 & 0 & 0 & 0 & 0 & 0 \\
\hline 20 & 0 & 0 & 0 & 0 & 0 & 0 & 0 & 0 & 0 & 0 & 0 & 0 & 0 & 0 \\
\hline 21 & 0 & 0 & 0 & 0 & 0 & 0 & 0 & 0 & 0 & 0 & 0 & 0 & 0 & 0 \\
\hline 22 & 0 & 0 & 0 & 0 & 0 & 0 & 0 & 0 & 0 & 0 & 0 & 0 & 0 & 0 \\
\hline 23 & 0 & 0 & 0 & 0 & 0 & 0 & 0 & 0 & 0 & 0 & 0 & 0 & 0 & 0 \\
\hline 24 & 0 & 0 & 0 & 0 & 0 & 0 & 0 & 0 & 0 & 0 & 0 & 0 & 0 & 0 \\
\hline 25 & 0 & 0 & 0 & 0 & 0 & 0 & 0 & 0 & 0 & 0 & 0 & 0 & 0 & 0 \\
\hline 26 & 0 & 0 & 0 & 0 & 0 & 0 & 0 & 0 & 0 & 0 & 0 & 0 & 0 & 0 \\
\hline 27 & 0 & 0 & 0 & 0 & a & 0 & 0 & 0 & 0 & 0 & 0 & 0 & 0 & 0 \\
\hline 28 & 0 & 0 & 0 & 0 & 0 & 0 & 0 & 0 & 0 & 0 & 0 & 0 & 0 & 0 \\
\hline 29 & 0 & 0 & 0 & 0 & 0 & 0 & 0 & 0 & 0 & 0 & 0 & 0 & 0 & 0 \\
\hline 30 & 0 & 0 & 0 & 0 & 0 & 0 & 0 & 0 & 0 & 0 & 0 & 0 & 0 & 0 \\
\hline 31 & 0 & 0 & 0 & 0 & 0 & 0 & 0 & 0 & 0 & 0 & 0 & 0 & 0 & 0 \\
\hline 32 & 0 & 0 & 0 & 0 & 0 & 0 & 0 & 0 & 0 & 0 & 0 & 0 & 0 & 0 \\
\hline 33 & 0 & 0 & 0 & 0 & 0 & 0 & 0 & 0 & 0 & 0 & 0 & 0 & 0 & 0 \\
\hline 34 & 0 & 0 & 0 & 0 & 0 & 0 & 0 & 0 & 0 & 0 & 0 & 0 & 0 & 0 \\
\hline 35 & 0 & 0 & 0 & 0 & 0 & 0 & 0 & 0 & 0 & 0 & 0 & 0 & 0 & 0 \\
\hline 36 & 0 & 0 & 0 & 0 & 0 & 0 & 0 & 0 & 0 & 0 & 0 & 0 & 0 & 0 \\
\hline 37 & 0 & 0 & 0 & 0 & 0 & 0 & 0 & 0 & 0 & 0 & 0 & 0 & 0 & 0 \\
\hline 38 & 0 & 0 & 0 & 0 & 0 & 0 & 0 & 0 & 0 & 0 & 0 & 0 & 0 & 0 \\
\hline 39 & 0 & 0 & 0 & 0 & 0 & 0 & 0 & 0 & 0 & 0 & 0 & 0 & 0 & 0 \\
\hline
\end{tabular}

Figure 6. Example of input file UserWLS.txt as shown in Microsoft Excel. Because of the large number of columns in this file, it is difficult to read in a text editor. 
matrix elements off the main diagonal may contain nonzero values. Figure 6 shows a portion of a UserWLS.txt file for a WLS regression problem.

\section{USGS\#\#\#\#\#\#.txt}

These files contain the annual-time series of interest for each streamflowgaging station used in the analysis. They are only used when the GLS option is selected. The Station ID should be substituted in the filename for the \#s. WREG looks for any file with "USGS" in the filename to use as input files. Consequently, no other files in the directory should have a filename containing USGS. WREG reads in each file sequentially in alphanumeric ascending order. ${ }^{2}$ An example file is shown in figure 7.

\begin{tabular}{|c|c|c|c|c|}
\hline \multicolumn{2}{|c|}{ 질 USG505314900 } & \multicolumn{3}{|c|}{$-\square x$} \\
\hline & A. & B & C & \\
\hline 1 & USGS05314900 & 1959 & 19 & \\
\hline 2 & USGS05314900 & 1960 & 228 & \\
\hline 3 & USGS05314900 & 1961 & 71 & \\
\hline 4 & USGS05314900 & 1962 & 472 & \\
\hline 5 & USGS05314900 & 1963 & 204 & \\
\hline 6 & USGS05314900 & 1964 & 126 & \\
\hline 7 & USGS05314900 & 1965 & 330 & \\
\hline 8 & USGS05314900 & 1966 & 142 & \\
\hline 9 & USGS05314900 & 1967 & 338 & \\
\hline 10 & USGS05314900 & 1968 & 187 & \\
\hline 11 & USGS05314900 & 1969 & 728 & \\
\hline 12 & USGS05314900 & 1970 & 191 & \\
\hline 13 & USGS05314900 & 1971 & 230 & \\
\hline 14 & USGS05314900 & 1972 & 82 & \\
\hline 15 & USGS05314900 & 1973 & 109 & \\
\hline 16 & USGS05314900 & 1974 & 8.8 & \\
\hline 17 & USGS05314900 & 1975 & 38 & \\
\hline 18 & USGS 05314900 & 1976 & 28 & \\
\hline 19 & USGS05314900 & 1977 & 148 & \\
\hline 20 & USGS05314900 & 1978 & 86 & \\
\hline 21 & USGS05314900 & 1979 & 120 & \\
\hline 22 & USGS05314900 & 1980 & 56 & \\
\hline 23 & USGS05314900 & 1981 & & \\
\hline 14 & $\cdots \rightarrow$ USGSO5 & ISI 1 & +1 & \\
\hline
\end{tabular}

Figure 7. An example of a USGS\#\#\#\#\#\#\#.txt file for streamflowgaging station 09183000.

${ }^{2}$ Other characters can be added to the filename, but they should be identical for each set of USGS\#\#\#\#\#\#\#.txt files. For example, a set of peak flow files could follow the naming convention USGS\#\#\#\#\#\#\#.peak.txt while a set of low-flow files could follow the naming convention USGS\#\#\#\#\#\#\#.lowflow.txt. Only one set of these files can be in the working directory at one time.
Each file should include three columns and $m$ rows, where $m$ is the number of years of record available at the streamflow-gaging station. The first column contains the site identifier Station ID that was used in the other input files. The second column contains the year, and the third column contains the value of the flow statistic during that year. For example, for a regression to estimate the $1 \%$ chance exceedance flood (Q100, the 100-year return period flood), the annualflow statistic entered in this file should be the annual-peak flow. The year may be a calendar year, water year, or climatic year, depending on what was used to define the annual series.

Note that even if more than one type of statistic is specified in the FlowChar.txt file, only one annualtime series can be entered in the USGS\#\#\#\#\#\#.txt file. Consequently, the USGS\#\#\#\#\#\#\#.txt files must be updated if a second time series is used to define the dependent variable. (In other words, the same USGS\#\#\#\#\#\#\#.txt files will not be valid for both peak flows and low flows.)

\section{Running the Program}

The WREG program uses a series of windows to guide the user through the formation, selection, and evaluation of a regression. The DOS window is displayed upon program execution, and will occasionally print information that monitors the progress of the program. Important information is always printed to a GUI window or to an output file.

Run the program by double-clicking on WREGv1.exe. If required input files are missing, the program will not run.

\section{Set Up Model}

\section{Select Variables}

The first window (fig. 8) is used to select variables (independent and dependent) for the regression. The items shown in the dependent variables menu

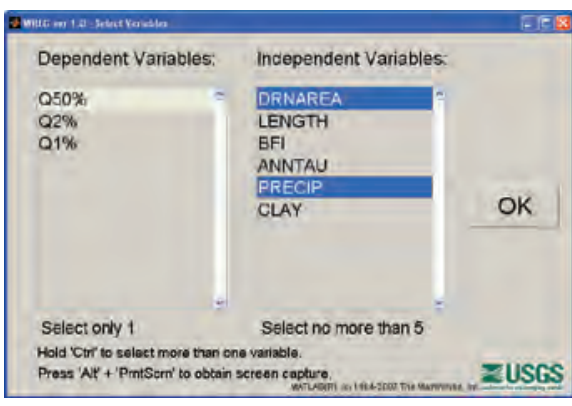

Figure 8. Example of WREG window used to select variables to be used in the regression.

and in the independent variables menu will depend on what has been included in the input files. One dependent variable should be selected. This is the flow statistic that will be estimated by the regression. To select more than one independent variable, hold down the CTRL key while clicking the left mouse button. Up to five independent variables can be selected.

\section{Select Transformations}

Each variable can be transformed by WREG (equation 5). Figure 9 shows the GUI window that facilitates variable transformation. The dependent variable and each independent variable are listed on the left of the window. In the middle part of this window, radio buttons are used to select whether to apply no transformations, to transform the variable using logarithms (base 10) $(\log 10[\ldots])$, using natural logarithms $(\ln [\ldots])$, or using an exponential function (e[...]). By default, no transformations are applied. In the right part of the window, additional transformations can be applied to the variable. The logarithmic or exponential transformation will be applied to the entire expression specified in the right half of the window. The default values that are displayed initially will result in no additional changes to the variable. $\mathrm{C} 1$ is used to multiply the variable by the constant $\mathrm{C} 1$. $\mathrm{C} 2$ is used to raise the variable to the power $\mathrm{C} 2$. $\mathrm{C} 3$ is used to add a constant $\mathrm{C} 3$ to the variable. $\mathrm{C} 4$ is used to raise the variable (including any algebraic transformation specified by $\mathrm{C} 1, \mathrm{C} 2$, or C3) to a power $\mathrm{C} 4$. 


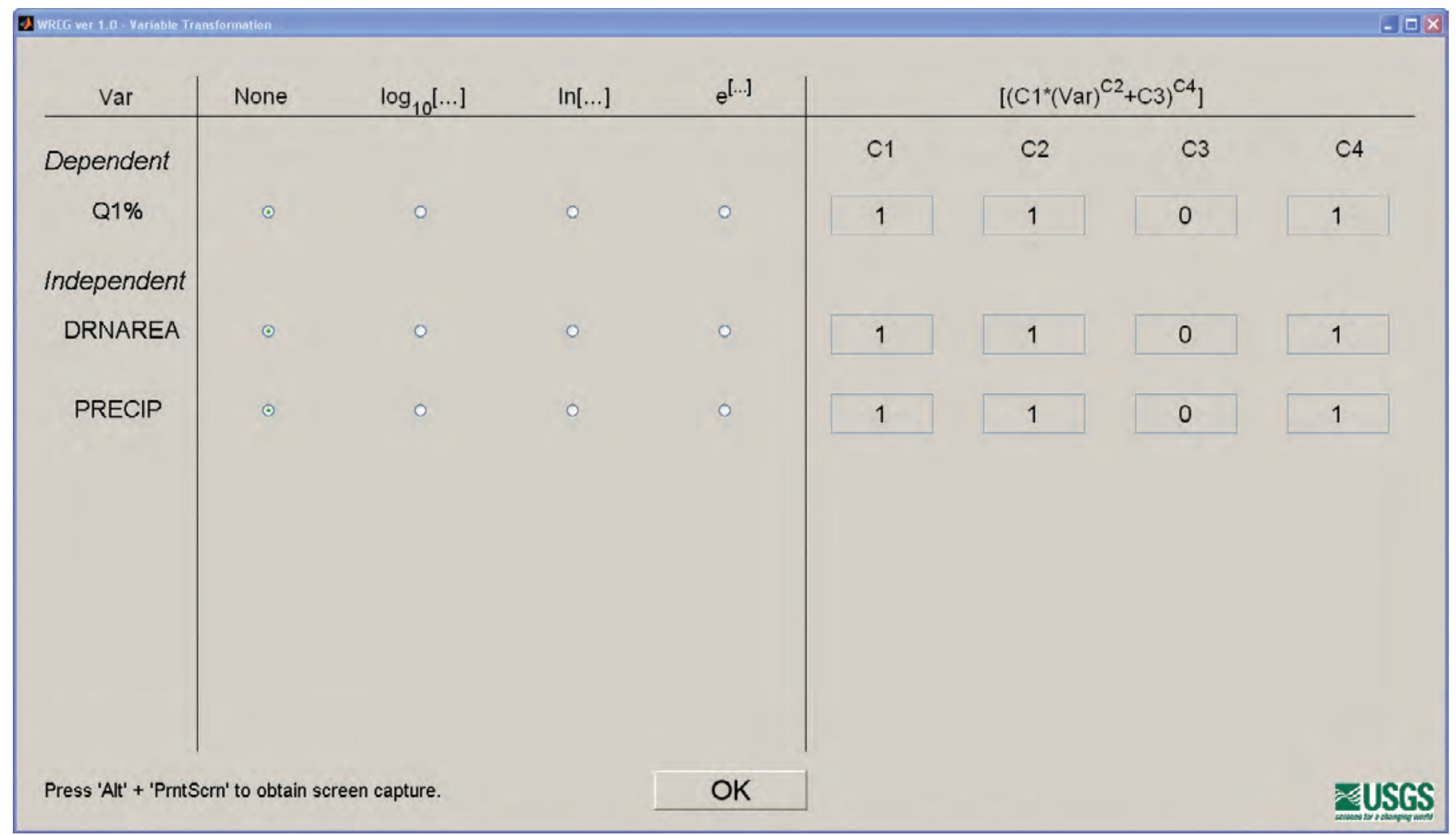

$A$

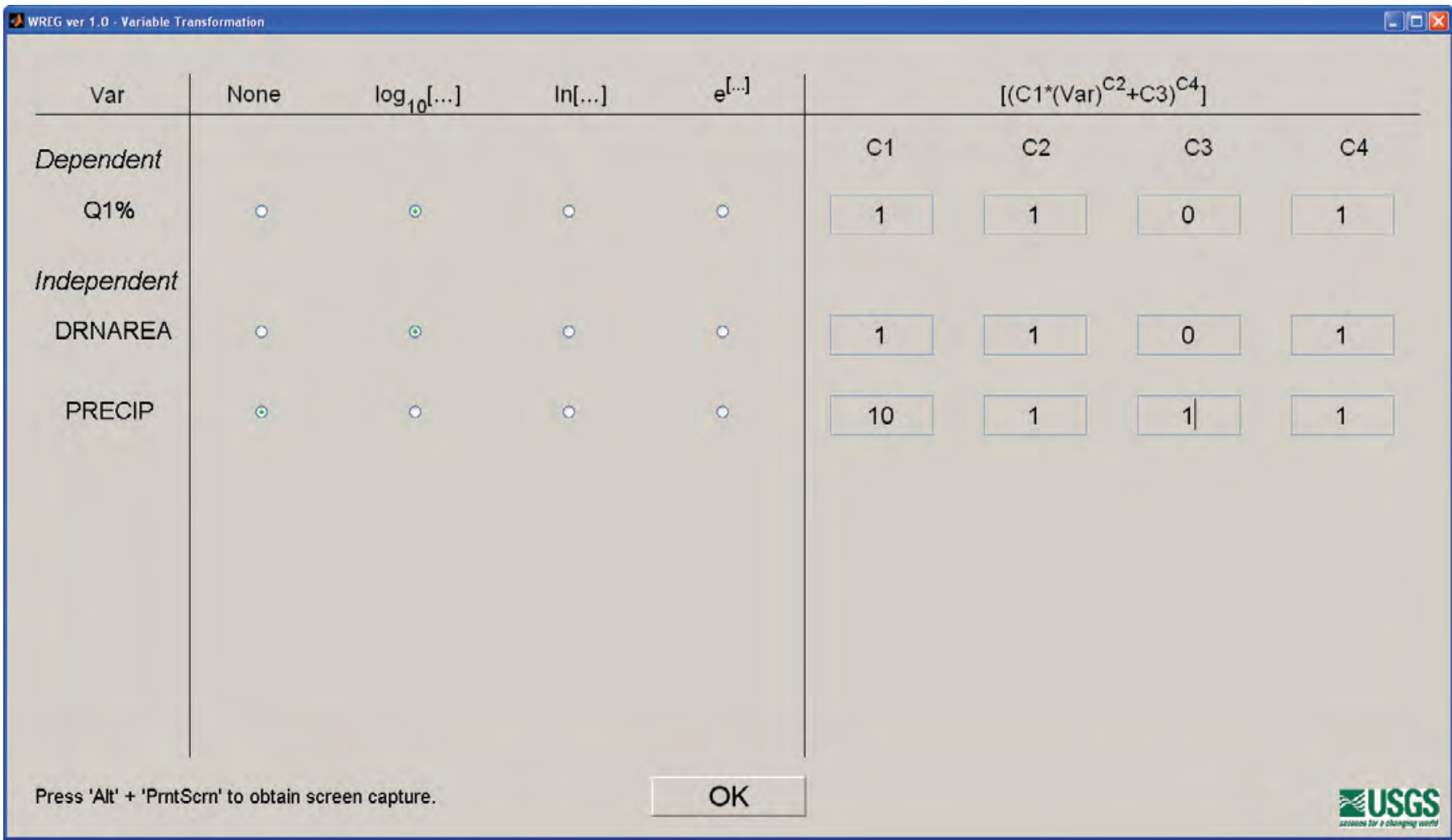

\section{$B$}

Figure 9. A, Example of WREG window for selecting transformations, as it initially appears. B, After transformations have been specified. 
For example, in figure $9 A$, the initial GUI window is shown, with no transformations selected. In figure $9 B$, selections will cause $1 \%$ chance exceedance flood (Q1\%) and the drainage area (DRNAREA) to be log (base 10) transformed. No further transformations will be applied to these variables. The annual precipitation (PRECIP) will first be multiplied by 10 and then a constant of 1 will be added to that quantity. These are merely illustrations of the use of the transformations, and are not intended to suggest useful transformations for these variables.

\section{Model Selection}

Either conventional regression or region-of-influence (RoI) regression can be selected by the radio buttons in the upper portion of the GUI window shown in figure 10. Equations formed by conventional regression can be used to estimate statistics at ungaged locations. WREG forms a RoI regression for each streamflow-gaging station in the database, allowing for evaluation of RoI as a regression strategy. However, WREG does not provide a function allowing the user to form a RoI regression for an ungaged location.

For RoI, the method for defining the region of influence must also be selected - either based on geographic proximity (GRoI), proximity in predictor variable space (PRoI), or a hybrid approach combining geographic and predictor variable space (HRoI). (These methods were discussed in the section Definition of Regions.) If using RoI, the number of sites, $n$, to use in the region must also be specified in the field under the RoI radio buttons. If the GRoI or HRoI method is selected, then the geographic proximity, $D$, must also be specified; this

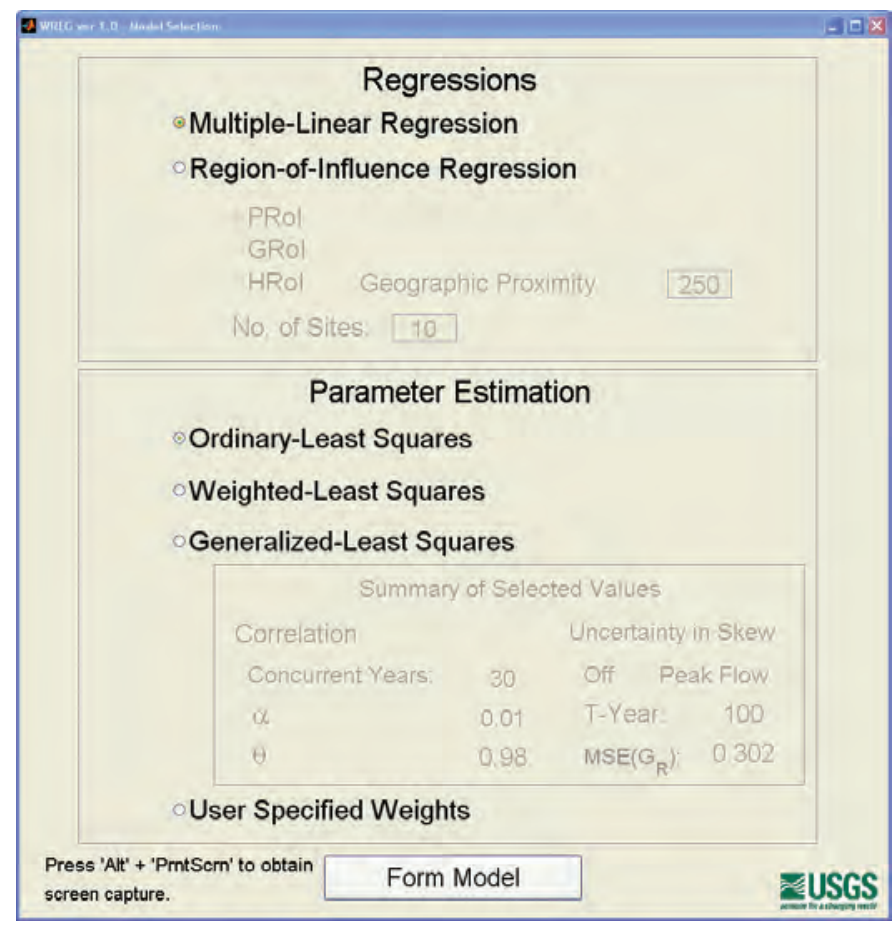

Figure 10. Example of WREG window for selecting the regression.

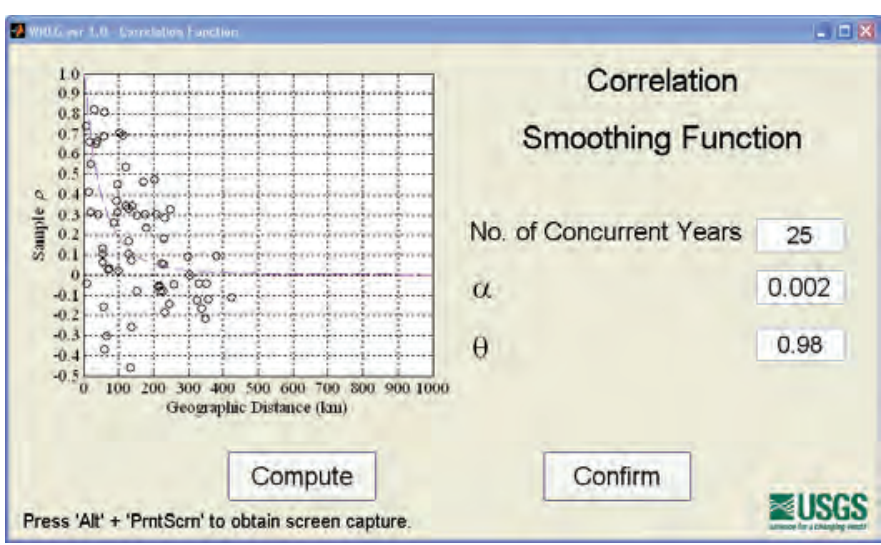

Figure 11. Example of WREG window for selecting parameters of the smoothing function for correlation as a function of distance between streamflow-gaging stations.

is the maximum distance from the ungaged location from which sites can be selected to form a region.

In the bottom panel of the same window (fig. 10), the parameter estimation method is selected using radio buttons as either ordinary least squares (OLS), weighted least squares (WLS), or generalized least squares (GLS).

If WLS or GLS is chosen, the program uses methods described earlier in this report to calculate the weighting matrix, $\boldsymbol{\Lambda}$. The USGS\#\#\#\#\#\#\#\#.txt files need to be supplied as input files if the GLS option is selected.

If conventional regression methods are used, there is also an option for utilizing user-specified weights in the regression. If UserWLS.txt was not supplied as an input file, an error message will appear if User Specified Weights is selected.

If a GLS regression is selected, a screen appears that allows adjustment of the parameters of a smoothing function (equation 18) that relates the correlation between streamflow time series (input in USGS\#\#\#\#\#\#\#\#.txt files) at two sites to the geographic distance between them, as shown in figure 11 . The default settings are a good starting point, but values can be adjusted to better fit specific datasets.

The "No. of Concurrent Years" specifies the minimum overlap among annual-peak flow records at streamflow-gaging stations before the correlation between them is used to estimate the smoothing function. If too few concurrent years are specified, the variability in correlation among streamflow-gaging stations may be too large to discern a relation between correlation and distance. However, if the required number of concurrent years is too large, there may not be enough data points to adequately define the relation. Generally, to fit well, the value of alpha, $\alpha$, will be positive and near zero while theta, $\theta$, will be slightly less than 1 . This combination of parameters causes the correlation to be near 1 when streamflow-gaging stations are very close, and to asymptotically approach a value near zero as the distance between them increases. When values are in this range, the closer $\theta$ is to one, the more slowly the correlation will decrease with distance. The closer $\alpha$ is to zero, the closer the asymptote will lie to zero.

After making desired changes to the parameters, click the "Compute" button to (re)compute and draw the smoothing 
function. The "Confirm" button will be grayed out while the program is computing the change. When satisfied with the fit of the smoothing function to the data, click the "Confirm" button.

Another window (fig. 12) will pop up that allows the uncertainty in skew to be considered in the regression calculations. [See section Generalized Least Squares (GLS).] This option should be used only if weighted skew was used in the calculation of the frequency statistics. The radio buttons are used to specify whether peak flows or low flows are being considered. Then the recurrence interval of the frequency statistic under consideration should be entered under $\mathrm{T}$-Year, and the mean square error of the regional skew should be entered under $\operatorname{MSE}\left(\mathrm{G}_{\mathrm{R}}\right)$. A default value of 0.302 is used in the program because this value is associated with plate I of Bulletin 17B of the Interagency Advisory Committee on Water Data (1982).

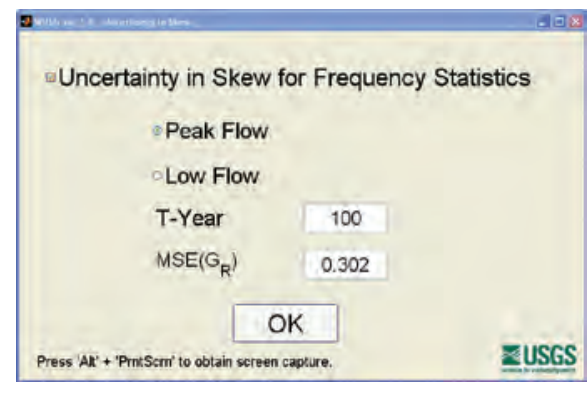

Figure 12. Example of WREG window for selecting option to include uncertainty in skew.

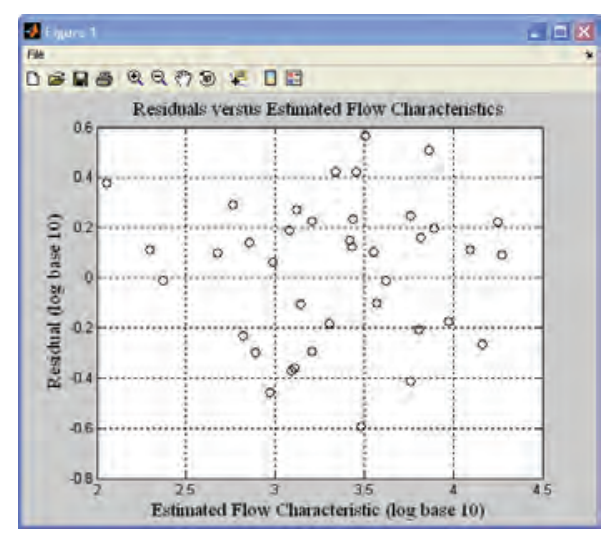

A

Figure 14. $A$, Example of plot showing residuals versus estimated flow characteristics. $B$, Example of plot showing leverage values versus observations. $C$, Example of plot showing influence values versus observations. performance metrics (appropriate to the type of regression used) and the regression equation. Elements of the regression equation that are shown in red are not statistically significant at the $5 \%$ level. Three plots accompany the regression output and are shown in figure 14. More detailed regression are calculated, the regression summary window (fig. 13) displays some basic

\section{Regression Summary}

\section{Performance Metrics:}

$$
S_{p}(\%)=
$$

$$
\text { Pseudo } \mathrm{R}^{2}=
$$

$$
\text { Standard Model Error }(\%)=
$$

$$
\begin{aligned}
\log _{10}\left[\left(1.00 *(Q 1 \%)^{1.00}+0.00\right)^{1.00}\right] & =1.15 \\
& +0.52^{*} \log _{10}\left[\left(1.00^{*}(\text { DRNAREA })^{1.00}+0.00\right)^{1.00}\right] \\
& +0.00 *\left(10.00^{*}(\text { PRECIP })^{1.00}+1.00\right)^{1.00}
\end{aligned}
$$

Indicates statistically insignificant $(p>0.05)$ independent variable.

Press 'Alt' + 'PrntScrn' to obtain screen capture.

Close

ZUSGS

Figure 13. WREG window showing the regression results for an GLS regression using the parameters and transformations specified in figure 9 .
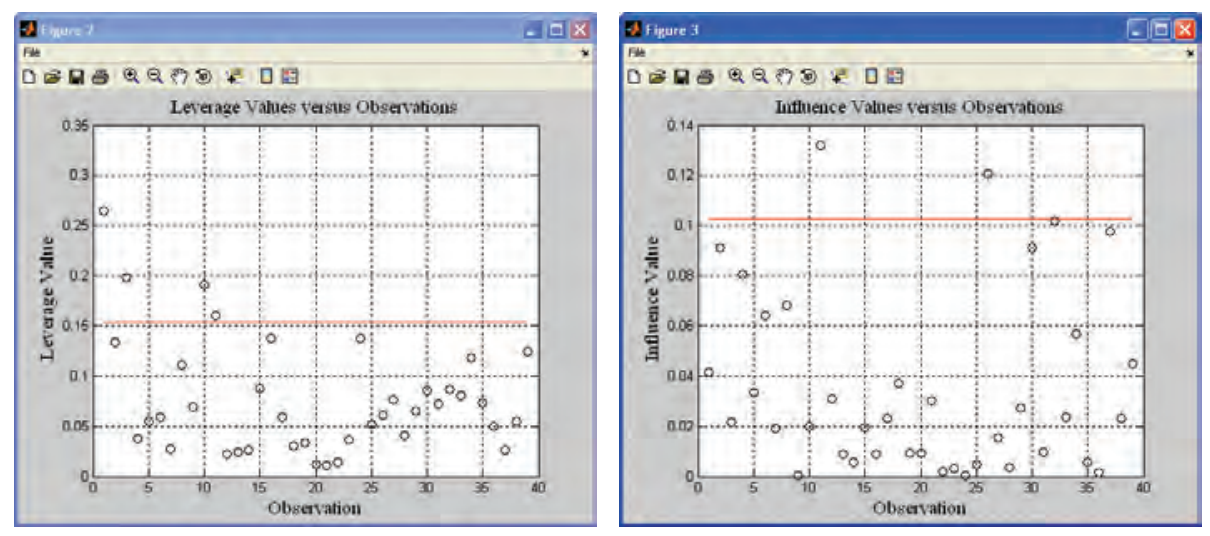

C

\section{Regression:}


results, including $\mathrm{p}$-values for individual parameters, are available in the text output files.

\section{Residuals Versus Estimated Flow Characteristics}

This plot (fig. 14A) shows the regression residuals (equation 28) plotted against the estimated flow characteristics. Both axes will be in units of the transformed flow characteristics [for example, log (base 10)].

\section{Leverage Values Versus Observations}

This plot (figure 14B) shows the leverage values plotted by observation number. Observations are numbered in the order in which they appear in the input files. The red line shows the threshold (as calculated by equation 41) above which an observation may be considered to have high leverage, as calculated by the appropriate equation for the type of regression, discussed earlier in the section Leverage and Influence Statistic. Observations with high leverage should be checked carefully for possible errors.

\section{Influence Values Versus Observations}

This plot (fig. 14C) shows influence values plotted by observation number. The red line shows the threshold (as calculated by equation 45) above which an observation may be considered to have large influence, as calculated by the appropriate equation for the type of regression, discussed earlier in the section Leverage and Influence Statistic. Observations with high influence should be checked carefully for possible errors.

\section{Output Files}

The output files are listed in table 2 with a brief description. A detailed description of each file's contents follows.

A text editor can be used to view all of the output files. Each file can also be imported into a spreadsheet program, such as Microsoft Excel, as a text, tab-delimited file.

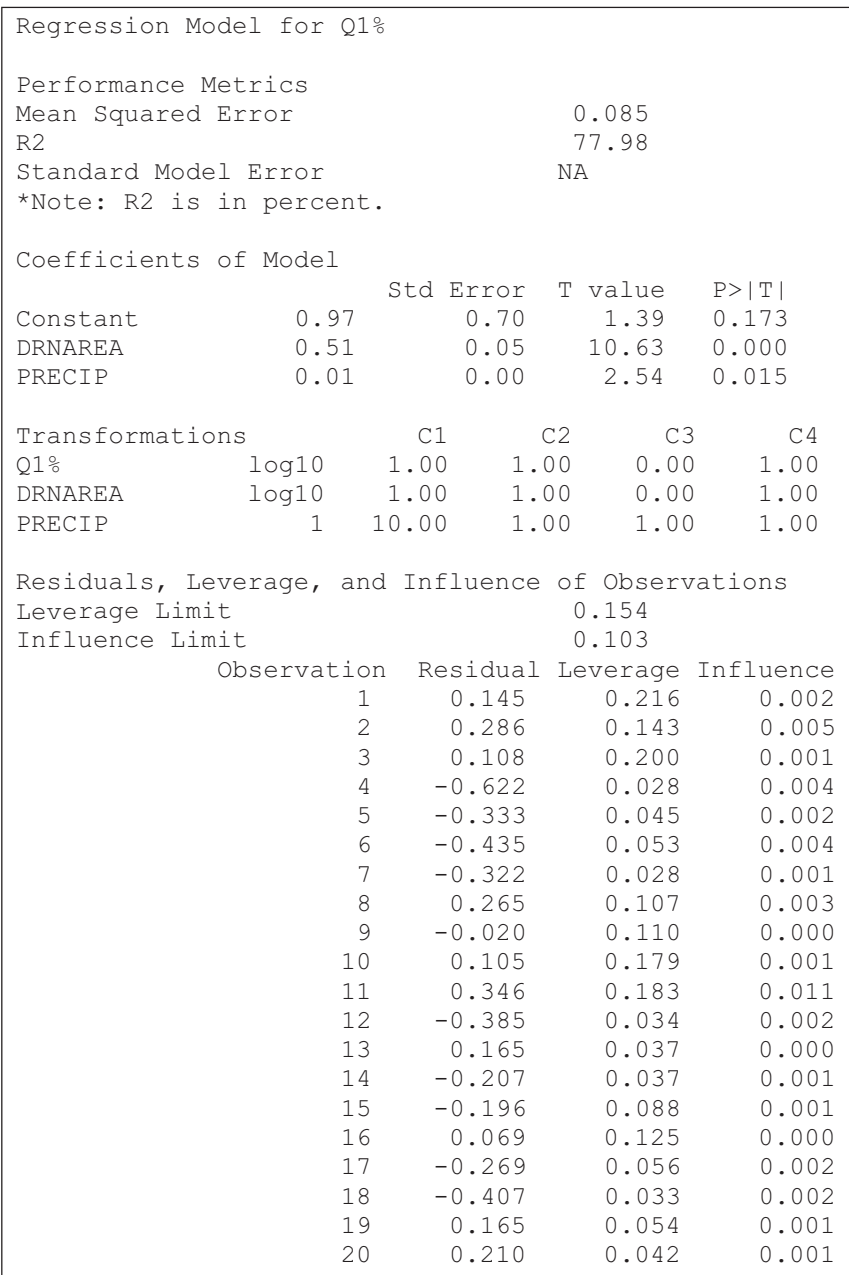

Figure 15. Example of output file ConventionalOLS.txt. Residuals, leverage, and influence are shown only for the first 20 observations.

Table 2. WREG output files.

\begin{tabular}{ll}
\hline \multicolumn{1}{c}{ File name } & \multicolumn{1}{c}{ Description } \\
\hline ConventionalGLS.txt & Results from a GLS regression. \\
ConventionalOLS.txt & Results from an OLS regression. \\
ConventionalWLS.txt & Results from a WLS regression. \\
RegionofInfluenceOLS.txt & Results from an OLS regression using RoI. \\
RegionofInfluenceWLS.txt & Results from a WLS regression using RoI. \\
RegionofInfluenceGLS.txt & Results from a GLS regression using RoI. \\
RegressionModel.txt & The regression equation (including transformations) calculated by WREG. Output only for conventional regression. \\
InvXLX.txt & Covariance of the regression parameters (equation 46). Output only for conventional regression. \\
SSres.txt & Residual sum of squares (equation 36). Output only for conventional regression. \\
SStot.txt & Total sum of squares (equation 37). Output only for conventional regression. \\
EventLog.txt & Record of the program's execution. Helpful for diagnosing runtime errors. \\
\hline
\end{tabular}




\section{ConventionalOLS.txt, ConventionalWLS.txt, and ConventionalGLS.txt}

These three files provide information on conventional regressions and are the same except for the performance metrics that are displayed at the head of the file. The metrics

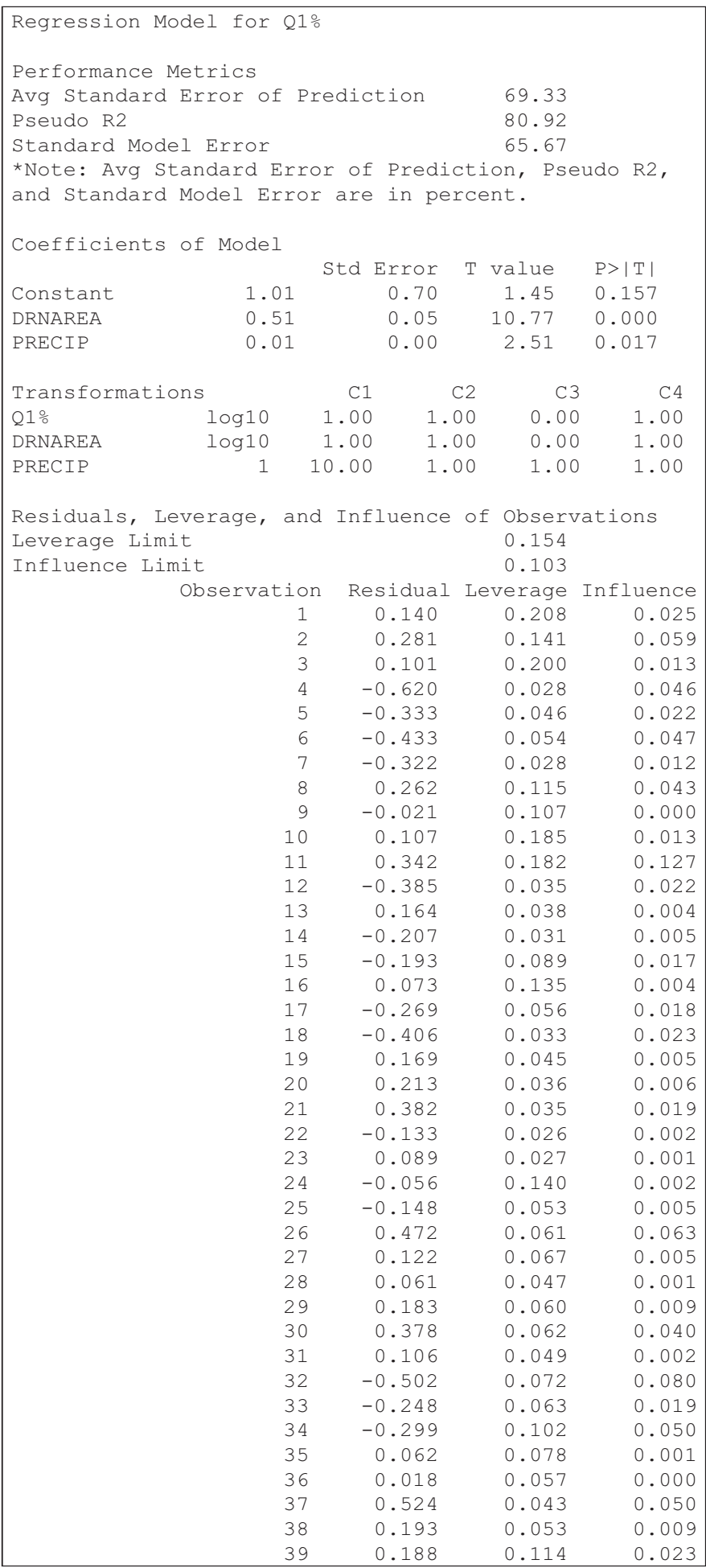

Figure 16. Example of output file ConventionalWLS.txt. shown are appropriate to the parameter selection scheme: OLS, WLS, or GLS. Figure 15 shows an example of output in ConventionalOLS.txt, figure 16 shows an example of output in ConventionalWLS.txt, and figure 17 shows an example of output in ConventionalGLS.txt.

\begin{tabular}{|c|c|c|c|c|c|}
\hline \multicolumn{6}{|l|}{ Regression Model for Q1\% } \\
\hline \multicolumn{6}{|l|}{ Performance Metrics } \\
\hline \multirow{2}{*}{\multicolumn{4}{|c|}{$\begin{array}{l}\text { Avg Standard Error of Prediction } \\
\text { Pseudo R2 }\end{array}$}} & \multicolumn{2}{|l|}{67.33} \\
\hline & & & & \multicolumn{2}{|l|}{82.43} \\
\hline \multicolumn{4}{|l|}{ Standard Model Error } & \multicolumn{2}{|l|}{62.55} \\
\hline \multicolumn{6}{|c|}{$\begin{array}{l}\text { "Note: Avg Standard Error of Prediction, Pseudo R2, } \\
\text { and Standard Model Error are in percent. }\end{array}$} \\
\hline \multicolumn{6}{|l|}{ Coefficients of Model } \\
\hline & Std E & Error & $\mathrm{T}$ & value & $\mathrm{P}>|\mathrm{T}|$ \\
\hline Constant & & 0.78 & & 1.49 & 0.146 \\
\hline DRNAREA & & 0.05 & & 10.94 & 0.000 \\
\hline PRECIP & & 0.00 & & 2.02 & 0.051 \\
\hline Transformations & $\mathrm{C} 1$ & & $\mathrm{C} 2$ & $\mathrm{C} 3$ & $\mathrm{C} 4$ \\
\hline $\log 10$ & 1.00 & & .00 & 0.00 & 1.00 \\
\hline DRNAREÀ & 1.00 & & .00 & 0.00 & 1.00 \\
\hline PRECIP & 10.00 & & .00 & 1.00 & 1.00 \\
\hline
\end{tabular}

Residuals, Leverage, and Influence of Observations Leverage Limit 0.154 Influence Limit 0.154 Observation Residual Leverage Influence $\begin{array}{lrr}0.139 & 0.265 & 0.042\end{array}$ $\begin{array}{lll}0.290 & 0.133 & 0.091\end{array}$ $\begin{array}{lll}0.112 & 0.199 & 0.021\end{array}$ $\begin{array}{lll}-0.592 & 0.037 & 0.080\end{array}$ $\begin{array}{lll}-0.301 & 0.055 & 0.033\end{array}$ $\begin{array}{lll}-0.411 & 0.059 & 0.064\end{array}$ $\begin{array}{lll}-0.293 & 0.027 & 0.019\end{array}$ $\begin{array}{lll}0.271 & 0.112 & 0.068\end{array}$ $\begin{array}{lll}-0.012 & 0.069 & 0.000\end{array}$ $0.111 \quad 0.191 \quad 0.020$ $\begin{array}{lll}0.378 & 0.161 & 0.132\end{array}$ $\begin{array}{lll}-0.359 & 0.022 & 0.031\end{array}$ $\begin{array}{lll}0.189 & 0.024 & 0.009\end{array}$ $\begin{array}{lll}-0.185 & 0.027 & 0.006\end{array}$ $\begin{array}{lll}-0.176 & 0.087 & 0.019\end{array}$ $\begin{array}{lll}0.091 & 0.138 & 0.009\end{array}$ $\begin{array}{lll}-0.233 & 0.058 & 0.023\end{array}$ $\begin{array}{lll}-0.373 & 0.030 & 0.037\end{array}$ $\begin{array}{lll}0.198 & 0.034 & 0.009\end{array}$ $\begin{array}{lll}0.245 & 0.011 & 0.009\end{array}$ $\begin{array}{lll}0.422 & 0.011 & 0.030\end{array}$ $\begin{array}{lll}-0.101 & 0.013 & 0.002\end{array}$ $\begin{array}{lll}0.121 & 0.036 & 0.003\end{array}$ $\begin{array}{lll}-0.011 & 0.138 & 0.000\end{array}$ $\begin{array}{lll}-0.105 & 0.051 & 0.005\end{array}$ $\begin{array}{lll}0.509 & 0.061 & 0.121\end{array}$ $\begin{array}{lll}0.161 & 0.076 & 0.015\end{array}$ $0.101 \quad 0.040 \quad 0.003$ $\begin{array}{lll}0.227 & 0.065 & 0.027\end{array}$ $\begin{array}{lll}0.423 & 0.085 & 0.091\end{array}$ $\begin{array}{lll}0.148 & 0.072 & 0.010\end{array}$ $\begin{array}{lll}-0.456 & 0.087 & 0.102\end{array}$ $\begin{array}{lll}-0.210 & 0.080 & 0.024\end{array}$ $\begin{array}{lll}-0.264 & 0.118 & 0.057\end{array}$ $0.100 \quad 0.073 \quad 0.005$ $\begin{array}{lll}0.061 & 0.050 & 0.001\end{array}$ $\begin{array}{lll}0.563 & 0.026 & 0.098\end{array}$ $\begin{array}{lll}0.236 & 0.054 & 0.023\end{array}$ $\begin{array}{lll}0.221 & 0.125 & 0.045\end{array}$

Figure 17. Example of output file ConventionalGLS.txt. 
The observations are the observed flow characteristic (dependent variable) at each streamflow-gaging station and are numbered in ascending order, as the stations appear in the FlowChar.txt file (and other files).

\section{RegionoflnfluenceOLS.txt, RegionoflnfluenceWLS. txt, and RegionoflnfluenceGLS.txt}

These three files show the same outputs but are produced using OLS, WLS, or GLS. The example shown in figure 18 is for RoI using OLS regression (RegionofInfluenceOLS.txt). This file provides information on the results of the RoI regression, and can be used to gauge whether an RoI regression may provide suitable results. However, WREG does not include a function that would allow users to perform a RoI regression at an ungaged location. The results shown by WREG are solely for demonstration or evaluation purposes.

WREG forms an individual RoI regression for each streamflow-gaging station included in the input dataset. The first several lines of the file show overall performance metrics for the RoI regression, when each of these individual regressions are considered. Next, the coefficients of the RoI regression built for each site in the dataset are shown. If 200 sites are included in the dataset, 200 results will be shownone for each regression that was built. These individual regressions will be numbered 1 to 200, and reflect the numerically ascending order of the Station IDs. That is, the Station ID with the smallest number would be associated with regression 1 or observation 1 in this output file and the Station ID with the largest number would be associated with the regression 200 or observation 200 in this output file.

The output file next displays the transformations that were used in the regressions. WREG does not allow different transformations to be used for different RoI regressions, and a single transformation applies to all individual RoI regressions formed by WREG. Next, the PRESS-like MSE of the RoI residuals are shown for the regression formed for each site in the dataset. Finally, the output file displays information on leverage and influence. For each regression, the output shows the observations that were used to form the regression as well as the leverage calculated for that observation. These outputs are paired. For example, in output shown in figure 18, the first regression used observations $2,8,3,9$, $14,13,12,7,10$, and 5. Following each observation number,

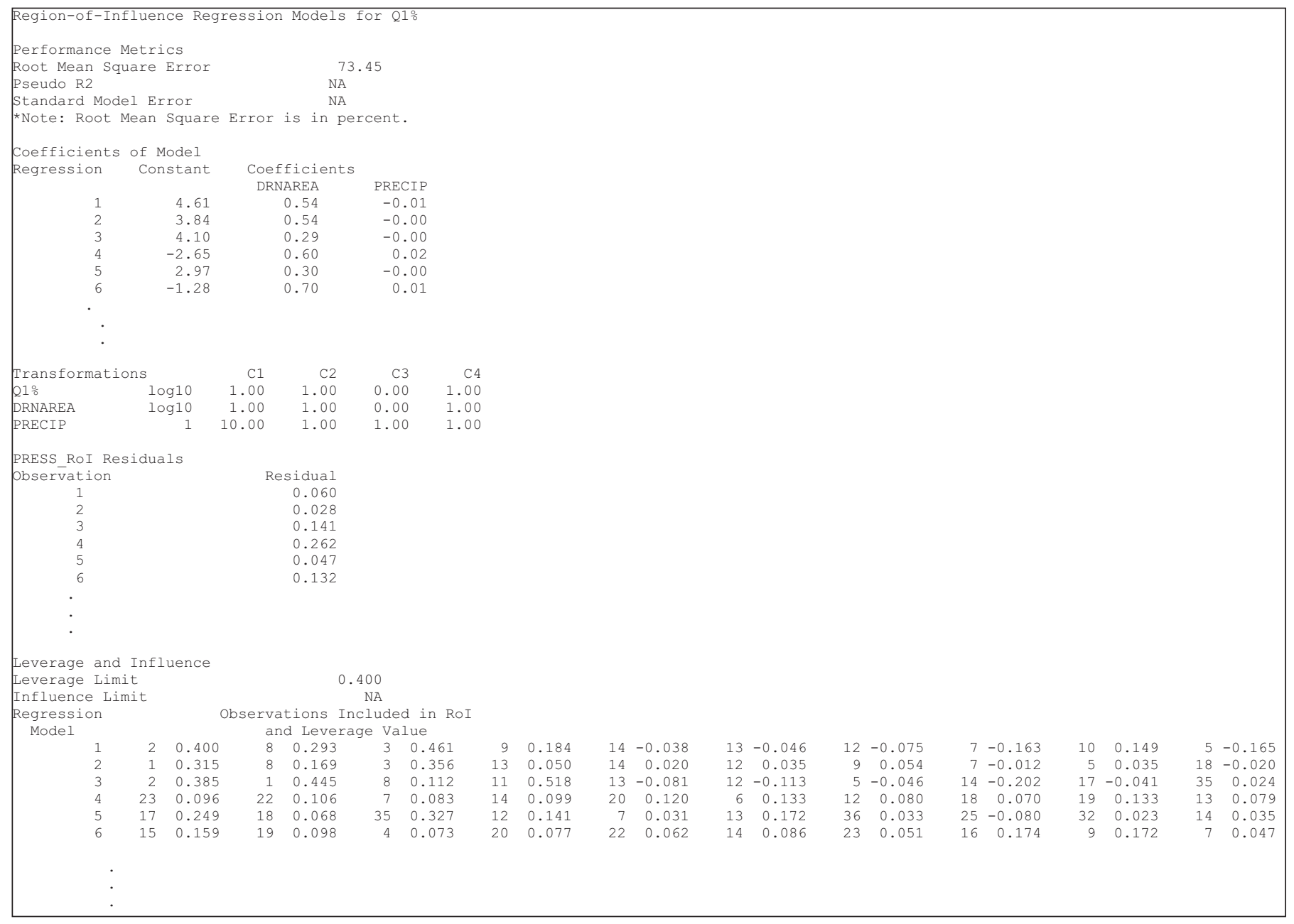

Figure 18. Example of output file RegionoflnfluenceOLS.txt. 
the leverage value for that observation is shown. For observation 2 , the leverage was 0.400 .

\section{RegressionModel.txt}

The RegressionModel.txt file gives the regression equation calculated by WREG. Transformations, variables, and parameters are all shown. In the example shown for conventional OLS (figs. 13 and 16), the corresponding regression equation contained in RegressionModel.txt is shown in figure 19. This equation can be interpreted as

$\log (Q 1 \%)=0.97+0.51 \log ($ DRNAREA $)+0.01(10$ Precip +1$) .(48)$

$\log 10\left\{\left[1.00 *(\mathrm{Q} 1 \%)^{\wedge}(1.00)+0.00\right]^{\wedge}(1.00)\right\}=1.15$
$+0.52 * \log 10\left\{\left[1.00 *(\text { DRNAREA })^{\wedge}(1.00)+0.00\right]^{\wedge}(1.00)\right\}$
$+0.00 *\left[10.00 *(\operatorname{PRECIP})^{\wedge}(1.00)+1.00\right]^{\wedge}(1.00)$

Figure 19. Example of regression model equation shown by RegressionModel.txt.

This output file is produced only for conventional regressions.

\section{InvXLX.txt}

This file contains the covariance matrix of the regression parameters (equation 46). Its size depends on the number of dependent variables used in the regression. An example is shown in figure 20. This matrix can be used to estimate the variance of individual regression estimates, which varies depending on the values of basin characteristics. This output file is created only for conventional regressions.

$6.0173594 e-001 \quad 1.4652262 e-003-1.8692077 e-003$

$1.4652262 e-003 \quad 2.2218603 e-003-1.4027835 e-005$

$-1.8692077 e-003-1.4027835 e-005 \quad 5.8799320 e-006$

Figure 20. Example of InvXLX.txt output file.

\section{SSres.txt and SStot.txt}

The SSres.txt file reports the residual sum of squares (equation 36) and the SStot.txt file reports the total sum of squares (equation 37). These output files are created only for conventional regressions. Examples are shown in figure 21.

$3.0515284 e+000$

A

Figure 21. Example of $A$, SSres.txt and $B$, SStot.txt output files.

$1.3821829 e+001$

\section{EventLog.txt}

The event log contains a record of the WREG session that can be useful for debugging. If the program is operating normally, it does not need to be considered.

\section{Other Program Notes}

Screen Capture.-As noted on many windows, the contents of that window can be captured by pressing Alt and the Print Screen key. This will copy an image of the window to the clipboard. It needs to be pasted into a document (for example, a WordPad document) in order to save it.

\section{Acknowledgments}

The authors would like to thank Jery R. Stedinger (Cornell University), Andrea M. Gruber-Veilleux (Cornell University), and Charles Parrett (USGS California Water Science Center) for their helpful comments on this report.

Future updates will be available at http://water.usgs.gov/software/WREG/.

\section{References Cited}

Acreman, M.C., and Wiltshire, S.E., 1987, Identification of regions for regional flood frequency analysis (abstract): EOS, v. 68 , no. 44.

Aitchison, J., and Brown, J.A.C., 1957, The lognormal distribution: Cambridge University Press, $176 \mathrm{p}$.

Burn, D.H., 1990, Evaluation of regional flood frequency analysis with a region of influence approach: Water Resources Research, v. 26, no. 10, p. 2257-2265.

Cook, R.D., 1977, Detection of influential observation in linear regression: Technometrics, v. 19, p. 15-18.

Eng, Ken, Tasker, G.D., and Milly, P.C.D., 2005, An analysis of region-of-influence methods for flood regionalization in the Gulf-Atlantic Rolling Plains: Journal of American Water Resources Association, v. 41, no. 1, p. 135-143.

Eng, Ken, Milly, P.C.D., and Tasker, G.D., 2007a, Flood regionalization: a hybrid geographic and predictor-variable region-of-influence regression method: Journal of Hydrologic Engineering, ASCE, v. 12, no. 6, p. 585-591.

Eng, Ken, Stedinger, J.R., and Gruber, A.M., 2007b, Regionalization of streamflow characteristics for the Gulf-Atlantic Rolling Plains using leverage-guided region-of-influence regression, Paper 40927-3050, in Kabbes, ed., Restoring our natural habitat - Proceedings of the World Environ- 
mental and Water Resources Congress, May 15-18, 2007, Tampa, Florida: American Society of Civil Engineers.

Funkhouser, J.E., Eng, Ken, and Moix, M.W., 2008, Lowflow characteristics for selected streams and regionalization of low-flow characteristics in Arkansas: U.S. Geological Survey Scientific Investigations Report 2008-5065, 161 p., available only online at http://pubs.usgs.gov/sir/2008/5065/. (Accessed August 19, 2009.)

Giese, G.L., and Mason, R.R., Jr., 1993, Low-flow characteristics of streams in North Carolina: U.S. Geological Survey Water Supply Paper 2403, 29 p., 2 plates. (Also available online at http://pubs.er.usgs.gov/usgspubs/wsp/wsp2403.)

Griffis, V.W., and Stedinger, J.R., 2007, The use of GLS regression in regional hydrologic analyses: Journal of Hydrology, v. 344, p. 82-95.

Griffis, V.W., and Stedinger, J.R., 2009, Log-Pearson type 3 distribution and its application in flood frequency analysis. III: sample skew and weighted skew estimators: Journal of Hydrologic Engineering, v. 14, no. 2, p. 121-130.

Hardison, C.H., 1971, Prediction error of regression estimates of streamflow characteristics at ungaged sites: U.S. Geological Survey Professional Paper 750-C, p. c228-c236. (Also available at http://pubs.er.usgs.gov/usgspubs/pp/pp750C.) (Accessed August 19, 2009.)

Hirsch, R.M., 1982, A comparison of four streamflow record extension techniques: Water Resources Research, v. 18, no. 4, p. 1081-1088.

Interagency Advisory Committee on Water Data, 1982, Guidelines for determining flood-flow frequency, Bulletin 17B of the Hydrology Subcommittee, Office of Water Data Coordination: U.S. Geological Survey, Reston, Va., 183 p. (Also available at http://water.usgs.gov/osw/bulletin17b/ dl_flow.pdf.) (Accessed August 19, 2009.)

Kenney, T.A., Wilkowske, C.D., and Wright, S.J., 2007, Methods for estimating magnitude and frequency of peak flows for natural streams in Utah: U.S. Geological Survey Scientific Investigations Report 2007-5158, 28 p. (Version 4.0 was released March 10, 2008, and is available only online at $h t t p: / / p u b s . u s g s . g o v /$ sir/2007/5158/.) (Accessed August 19, 2009.)

Kite, G.W., 1975, Confidence limits for design events: Water Resources Research, v. 11, no. 1, p. 48-53.

Kite, G.W., 1976, Reply to comment on Confidence limits for design events: Water Resources Research, v. 12, no. 4, p. 826.

Martins, E.S., and Stedinger, J.R., 2002, Cross correlations among estimators of shape: Water Resources Research, v. 38 , no. 11, p. 34-1-34-7, doi:10.1029/2002WR001589.

Merz, R., and Blöschl, G., 2005, Flood frequency regionalisation - spatial proximity vs. catchment attributes: Journal of Hydrology, v. 302, p. 283-306.
Montgomery, D.C., Peck, E.A., and Vining, G.G., 2001, Introduction to linear regression analysis ( $3 \mathrm{~d}$ ed.): New York, John Wiley and Sons, $641 \mathrm{p}$.

Neely, B.L., Jr., 1986, Magnitude and frequency of floods in Arkansas: U.S. Geological Survey Water Resources Investigations Report 86-4335, 51 p., available only online at http://pubs.er.usgs.gov/usgspubs/wri/wri864335/. (Accessed August 19, 2009.)

Ries, K.G., III, and Fries, 2000, Methods for estimating low-flow statistics for Massachusetts streams: U.S. Geological Survey Water-Resources Investigations Report 2000-4135, 81p. (Also available at http://pubs.usgs.gov/wri/ wri004135/.) (Accessed August 24, 2009.)

Ries, K.G., III, comp., 2007, The National Streamflow Statistics Program: A computer program for estimating streamflow statistics for ungaged sites: U.S. Geological Survey Techniques and Methods book 4, chap. A6, 45 p. (Also available at $h t t p: / / p u b s . u s g s . g o v / t m / 2006 / t m 4 a 6 /$. (Accessed August 19, 2009.)

Stedinger, J.R., and Tasker, G.D., 1985, Regional hydrologic analysis, 1, ordinary, weighted, and generalized least squares compared: Water Resources Research, v. 21, no. 9, p. 1421-1432.

Stedinger, J.R., and Tasker, G.D., 1986, Regional hydrologic analysis, 2, model-error estimators, estimation of sigma and log-Pearson Type 3 distributions: Water Resources Research, v. 22, no. 10, p. 1487-1499.

Tasker, G.D., 1980, Hydrologic regression with weighted least squares: Water Resources Research, v. 16, no. 6, p. 1107-1113.

Tasker, G.D., and Stedinger, J.R., 1986, Regional skew with weighted LS regression: Journal of Water Resources Planning and Management, ASCE, v. 112, no. 2, p. 225-236.

Tasker, G.D., and Stedinger, J.R., 1989, An operational GLS model for hydrologic regression: Journal of Hydrology, v. 111, p. 361-375.

Tasker, G.D., Hodge, S.A., and Barks, C.S., 1996, Region of influence regression for estimating the 50-year flood at ungaged sites: Water Resources Bulletin, v. 32, no. 1, p. $163-170$.

Thomas, D.M., and Benson, M.A., 1970, Generalization of streamflow characteristics from drainage-basin characteristics: U.S. Geological Survey Water-Supply Paper 1975, 55 p. (Also available online at http://pubs.er.usgs.gov/ usgspubs/wsp/wsp 1975.) (Accessed August 19, 2009.)

Wandle, S.W., 1977, Estimating the magnitude and frequency of floods on natural-flow streams in Massachusetts: U.S. Geological Survey Water-Resources Investigations Report 77-39, 26 p., 1 plate. (Also available online at http://pubs.er.usgs.gov/usgspubs/wri/wri7739.) 

